\title{
Rhetoric versus Reality: The Best and Worst of Aid Agency Practices
}

\author{
William Easterly \& Claudia R. Williamson ${ }^{*}$
}

JEL: O1; F5

* William Easterly (William.easterly@nyu.edu) NYU and NBER, and Claudia Williamson (Claudia.williamson@nyu.edu) Development Research Institute, New York University, 19 W. $4^{\text {th }}$ St, New York, New York 10012. 
Acknowledgements: We thank Polina Minkovski and Nobuyuki Kanazawa for valuable research assistance. 


\begin{abstract}
Foreign aid critics, supporters, recipients and donors have produced eloquent rhetoric on the need for better aid practices - has this translated into reality? This paper attempts to monitor the best and worst of aid practices among bilateral, multilateral, and UN agencies. We create aid practice measures based on aid transparency, specialization, selectivity, ineffective aid channels and overhead costs. We rate donor agencies from best to worst on aid practices. We find that the UK does well among bilateral agencies, the US is below average, and Scandinavian donors do surprisingly poorly. The biggest difference is between the UN agencies, who mostly rank in the bottom half of donors, and everyone else. Average performance of all agencies on transparency, fragmentation, and selectivity is still very poor. The paper also assesses trends in best practices over time - we find modest improvement in transparency and more in moving away from ineffective channels. However, we find no evidence of improvements (and partial evidence of worsening) in specialization, fragmentation, and selectivity, despite escalating rhetoric to the contrary.
\end{abstract}

Keywords: Foreign Aid, Best Practices, Transparency, Bureaucracy, Incentives 


\section{INTRODUCTION}

"We, Ministers of developed and developing countries responsible for promoting development and Heads of multilateral and bilateral development institutions...resolve to take far-reaching and monitorable actions to reform the ways we deliver and manage aid...we recognize that while the volumes of aid and other development resources must increase to achieve these goals, aid effectiveness must increase significantly as well to support partner country efforts to strengthen governance and improve development performance."

Paris Declaration on Aid Effectiveness (2005, p.1)

Despite the transfer of over $\$ 4.6$ trillion (measured in constant 2007 dollars) in gross official development assistance (ODA) to developing countries from 1960 through 2008, a substantial amount of the world remains in extreme poverty and stagnant growth ${ }^{1}$ ([Bauer, 2000], [Easterly, 2001, 2006] and [Moyo, 2009]). ${ }^{2}$ The aid community now emphasizes improved quality of the delivery and allocation of official aid as a necessary means to achieve positive outcomes (for example, see the [Paris Declaration on Aid Effectiveness, 2005], which was followed up by the [Accra Agenda for Action, 2008]). Unfortunately, there is no disaggregated data available on the impact of aid on the beneficiaries, which would be the most desirable measure of quality of aid. Like others in this literature, we follow a more indirect approach. We focus on five dimensions of agency ‘best practices’ derived from what practices the donors themselves, outside aid monitors, and the academic literature suggest agencies should follow. We use the Paris and Accra process as another reference point among many on what the consensus on best 
practices is. However, as explained below, we choose not to directly monitor compliance with Paris and Accra agreements, as these agreements are a negotiated political process rather than an academic monitoring exercise.

The five best practice dimensions are based on Easterly and Pfutze's (2008) best practices, which are agency transparency, minimal overhead costs, fragmentation of aid, delivery to more effective channels, and allocation to less corrupt, more democratically free, poor countries. Transparency is based on the ability to gather information such as employment numbers, budgetary data, and overhead costs. Specialization captures the extent to which aid is divided among many donors, many countries, and many sectors. Selectivity refers to aid delivery to the poorest countries while avoiding corrupt dictators. Ineffective channels measures the share of aid that is tied, given as food aid or as technical assistance. Overhead cost utilizes the data collected during the transparency stage and refers to an agencies' costs relative to aid disbursements. These concepts reflect standards identified over a number of years of research on the need to reform the allocation and management of foreign aid ([Rome Declaration, 2003], [Roodman, 2006, 2009], [Center for Global Development, 2007], [Knack and Rahman, 2007], [Commission for Africa, 2005], [IMF and World Bank, 2005, 2006], [Paris Declaration, 2005], [United Nations Development Program, 2005], [United Nation Millennium Project, 2005], [Easterly, 2007], [Accra Agenda, 2008], [Easterly and Pfutze, 2008], [Birdsall, Kharas, Mahgoub, and Perakis, 2010] and [Knack, Rogers, and Eubank 2010]). We will provide more detailed justification and references in the section on each concept below. 
We acknowledge that there is no direct evidence that our indirect measures necessarily map into improved impact of aid on the intended beneficiaries. We will also point out specific occasions where the relationship between our measures and desirable outcomes could be non-monotonic or ambiguous. We primarily emphasize outliers that are less ambiguous. We focus on best practice as one constructive input into the aid system as a whole working well. So for example, we think aid is unlikely to be a healthy system if donors refuse to disclose information on their activities, if even the smallest aid agencies fragment their assistance into dozens of different country and sector programs, if most aid money is given to corrupt dictators, if most of aid is tied to purchases of goods or consultants from the donor, and if overhead costs take up much of aid disbursements.

This focus addresses two general questions in the wider aid debate: 1) do agencies perform the way they say they should and 2) are agencies moving towards 1 ) over time? The analysis attempts to sort out agency rhetoric from reality by contrasting what agencies are saying with what they are actually doing. We do so by monitoring individual bilateral and multilateral aid agencies, including the UN agencies, compared to the best practices outlined above. From these measures, we remark on the improvement, or lack thereof, of agency practices among individual donors over the past five years and for the international aid effort as a whole dating back to 1960 (when possible). We simply take the best practice measures as stated from the aid community and the aid literature as given and focus the analysis on ranking individual aid agencies compared to these practices.

The paper has several main results. As emphasized in previous aid studies, "the data on aid agency spending are inexcusably poor” (Easterly and Pfutze, 2008, p. 3). 
Unfortunately, the current state of aid data remains appallingly inconsistent making it difficult to compare best practices across donors and overtime. This finding makes the recent attempt by AidData to collect consistent and comprehensive data on development finance all the more valuable (Tierney et al., 2011). ${ }^{3}$ Most of our data on donor allocation of aid is taken from the OECD Development Assistance Committee (DAC) but reporting is voluntary and a number of agencies do not participate. In addition, less than half of the agencies directly contacted for this study actually responded. This general finding lends support to the conclusion that agencies are not nearly as transparent as they need to be, making consistent and accurate monitoring all the more difficult. When possible, we compare changes in donor transparency and do find a slight trend toward an increase in agency transparency.

The data that is available suggests that the overall international aid community continues to suffer from many of the problems previously identified. Aid is fragmented among many donors, large and small, and donors do not specialize, splintering aid allocation among many countries and many sectors. Donors continue to allocate aid to corrupt and unfree countries, even taking into account the worthy aim of directing aid to poor countries. In short, aid community criticizes these practices but continues them anyway.

Based these measures of best practices, we create an overall aid agency ranking. Who are the best and worst performers on aid practices? The Global Fund is the best multilateral and the United Kingdom is the best among the bilateral agencies, ranking second overall. Greece ranks last overall. 
We look for patterns relative to well known priors among aid observers - do the Scandinavian countries deserve their good reputation among bilaterals? Does the different governance structure of the UN agencies (such as more diluted governance based on equal voting rights in the General Assembly) result in differential performance relative to other multilaterals? (The answers turn out to be (1) no, and (2) yes.). We will also pay special attention to the US as a donor, because the politics of aid in the US are fairly well known.

The paper also assesses trends in best practices over time, updating the work of Easterly (2007) where data permits. Our results are that there has been substantial improvement in discontinuing ineffective channels of aid delivery, and a little improvement in transparency. However, aid fragmentation and selectivity favoring noncorrupt democratic donors continue to show no improvement over very poor performance, despite the escalation of rhetoric and Paris Declaration (2005) commitments (frequently reiterated every year, such as Accra [2008])

\section{LITERATURE REVIEW}

There has been a welcome surge in the literature on monitoring, evaluating, and rating aid agencies’ performance. Before explaining how our study adds value relative to other studies, we first note that this literature is still at an early stage and is still undersupplying the public good of independent commentary on aid agencies’ performance. As pointed out by many authors, aid agencies lack the normal feedback loops available to democratic or market actors, who can observe dissatisfaction of voters or customers. Aid beneficiaries have no vote and no purchase decisions by which they 
could communicate dissatisfaction to aid agencies. This makes a variety of independent academic checks on aid agencies useful to fill the void. So we first welcome the recent collection of recent papers using apparently similar methods to achieve apparently similar objectives, yet still offering important differences in both methods and objectives to this paper.

We organize our discussion of the literature and our paper's marginal contribution around several important issues. The first issue is how closely to track the aid donors' Paris Declaration (2005) and Accra Agenda (2008) process on improving aid effectiveness. Knack, Rogers, and Eubank (2010) closely follow the content and main indicators outlined in the Paris Declaration when selecting which components to include in the analysis. A second study by Birdsall, Kharas, Mahgoub, and Perakis (2010) parallels Knack, Roger, and Eubank (2010) also using the Paris Monitoring Indicators to motivate their dimensions of focus. These studies are very useful to answer the question if donors are keeping their commitments under the Paris Declaration, the current major international effort for reform in aid practices. Nonetheless, our paper chooses not to follow the Paris Declaration so closely. While the Paris Declaration itself is important evidence on the donor consensus on best practices (to which we also appeal like other studies), the Declaration also introduced its own methods and indicators for monitoring these practices. Since the Paris Declaration process itself is an institutional and political process and not an academic exercise, we believe it is also valuable for us to provide an aid monitoring exercise based on our own choices on the best methods for monitoring on academic grounds alone. 
A second related issue is how broad to make the monitoring exercise, or in other words, how broad to make the concept being monitored. Most of the other papers in this literature choose broader concepts than we do. Birdsall et al. (2010) and Knack et al. (2010) use Aid Quality as their desired concept, while the high profile exercise described in Roodman (2006, 2009) uses Commitment to Development. There is a tradeoff between a broader concept that provides a more comprehensive picture, on one hand, and the lack of clarity of the precise definition or measurement of a broad concept, on the other. We choose to focus on the more precise and measurable concept of Aid Best Practices.

A third issue is whether to monitor donors' absolute or conditional performance. A priori, conditional performance measures have a strong appeal as controlling for factors beyond the donors' control. This is usually done with regression methods controlling for such factors. For example, Dollar and Levin (2006) rank agencies based on a policy selectivity index that captures whether donors consider a recipient county's institutional and policy environment before allocating aid, controlling for policies and population. The most ambitious and persuasive effort along these lines is Knack, Rogers, and Eubank (2010), which controls for factors like an agency’s geographic range when monitoring their behavior.

These studies provide valuable information, but we believe that measuring absolute performance (as our paper will do) is also important and insightful. Once the Pandora's box of conditioning factors is opened, it is very hard to decide where to begin or where to stop. For example, Knack et al. (2010) follows Dollar and Levin in measuring donors' sensitivity to income controlling for policy and population. It is arguable whether population should be a control, since it winds up reflecting the small 
country bias of most aid donors, and one wonders whether small country bias should be a valid excuse for not having better poverty or democracy selectivity. The conditioning process is also sensitive to errors in variables. For example, the World Bank’s Country Policy and Institutional Assessment (CPIA) is used by both Dollar and Levin and Knack et al., yet is arguably biased in favor of countries with which the Bank wants or needs to maintain a long run relationship for other reasons. Finally, Knack et al. control for aspects of the aid agency's mission or geographic reach. Ex-post, this is obviously beyond the aid agency’s control. However, we may want to comment on what kinds of agency mission statements or geographic restrictions lead to better or worse performance. For all of these reasons, we believe the absolute performance measures that we use are a valuable alternative methodology. We will still be able to discuss the factors beyond agency control that affect the absolute performance of individual agencies as we describe the outcomes.

Yet another dimension in this literature is whether to emphasize snapshots at one moment in time, or to analyze trends in aid performance. The only other paper to include systematic trends is the Commitment to Development Index, which can now compare the 2010 edition to the first edition in 2003. Because of our narrower focus, in addition to current snapshots, we can also offer trends going back into the 1960s or 1970s, which allows us to address important issues such as whether aid practices changed in the wake of major international changes like the end of the Cold War and the beginning of the War on Terror, or major changes in aid rhetoric, such as that concerning democracy and corruption in the mid-1990s. We have been using, learning, and cleaning the same datasets for a long while now (see [Easterly and Pfutze, 2008] and [Easterly, 2007]), and 
we believe this continuity contributes to the value of this exercise, while at the same time we present new results. We present several examples below how the "snapshot” view can reflect one-time flukes, hence the importance of multi-year monitoring.

For all of these reasons, there is surprisingly limited overlap between our studies and others, which at first blush appear similar. For Birdsall et al. (2010), only seven of their thirty indicators overlap with ours. For Knack et al. (2010), it is five out of their eighteen. For the Commitment to Development Index, we overlap on selectivity and aid tying, but aid practice is only a part of the CDI aid component, which in turn is only one out of seven components of the CDI. The overlapping indicators also play a small role in our exercise. And even for the overlapping indicators, our methodology is different in the ways described above.

In summary, we suggest this paper offers significant valued added relative to the other papers in the literature. We also acknowledge the significant contributions made by these other papers, and believe we are still in the "let a thousand flowers bloom" phase of the aid agency monitoring literature.

Again we cannot emphasize enough that all of the studies in this literature, including ours, leave out any direct measurement of the impact of aid dollars on the intended beneficiaries. This would be highly desirable to monitor but there are simply no reliable impact measures available across agencies (or for aid in general at any detailed level in most cases). For the same reason, all of the studies (including ours) cannot demonstrate evidence that our measures of aid quality or aid practices are directly related to aid impact, since again we have no measure of the latter. All studies in this literature 
have to appeal instead to a common sense consensus that very bad performance on the indicators would make a strong positive aid impact less likely.

\section{AGENCY BEST AND WORST PRACTICES}

Why focus on best practices? As discussed above, and in more detail below, best practices are measurable indicators that could allow observers to monitor donors, as one small contribution to overcoming the problem of missing feedback and accountability, a problem that is well-documented in the literature ([IMF and World Bank, 2005], [Martens, Mummert, Murrell, and Seabright, 2002] and [Easterly 2006]). We follow the established methodology on how to measure best practices taking into consideration some recent criticisms (for example, see BenYishay and Wiebe, 2009). ${ }^{4}$

The names of bilateral donors are obviously just the country names, we combine agencies when there is more than one per country. In the end, the analysis included 31 bilateral agencies from 23 donor countries. The paper does not include donors from nonDAC countries such as China, Poland, or Turkey, which have extremely limited data.

Table 1 lists the multilateral agencies in the analysis along with a brief description. There are 10 non-UN multilateral agencies and $10 \mathrm{UN}$ agencies. The multilaterals range from international development banks such as the World Bank (IBRD \& IDA), to more focused agencies such as the United Nation's World Food Program (WFP).

\section{TABLE 1 INSERTED HERE}

The general methodology in each area is to measure several different indices of performance on practices. We will then take a weighted average of the measures if they 
are measuring commensurate concepts, such as Herfindhals (the weights are usually equal, with the exceptions noted below).

If the sub-indicators are not commensurate, then we convert each sub-indicator into a percentile ranking on that sub-indicator, and do the average over the percentile ranks to get an overall ranking for each indicator. We will follow the same methodology to get an overall composite index - i.e. the average of five percentile rankings will give an aggregate score for all agencies. ${ }^{5}$

\section{(a) Transparency}

The first component, and possibly the most important, is agency transparency. This entails the ability for those outside the organization to obtain access to information about the operations of the agency. Examples include the number of employees and staff, a breakdown of overall agency expenditures, including aid disbursements, administrative costs, and expenditures on salaries and benefits. Without transparency, independent commentators cannot monitor aid agencies. Aid recipients have no mechanism to hold agencies responsible and taxpayers in donor countries cannot monitor aid practices, as it is virtually impossible to track where the money goes.

The absence of feedback from aid recipients is widely regarded as one of the fundamental problems with aid effectiveness. The international aid community now calls for greater transparency to remedy the lack of feedback and to improve incentives for effective aid allocation. In fact, transparency is the latest buzzword among the aid community. According to the Paris Declaration on Aid Effectiveness (2005, p.1), donors commit to “(e)nhancing donors’ and partner countries’ respective accountability to their citizens and parliaments for their development policies, strategies and performance...(A) 
lack of transparency, which erode public support, impede(s) effective resource mobilisation and allocation and divert(s) resources away from activities that are vital for poverty reduction and sustainable economic development."

In order to measure transparency, we follow the methodology established by Easterly and Pfutze (2008) (EP), explained in detail below. Due to very limited data on agency transparency, the only possible way to monitor changes in agency transparency over time is to compare our rankings to EP's transparency rankings. Although this is not an ideal test, this is a first attempt to try and measure changes in agency transparency over time. We discuss this further in section 4.1 below.

To monitor agencies based on transparency, we create two different indices from two main sources. To construct the first index, we utilize data from the International Development Statistics provided by the OECD reporting system. Reporting to the OECD system is a first step towards greater agency transparency as it provides the public with information on the allocation of aid expenditures. If an agency reports to one of five OECD tables for bilateral agencies and to one of three OECD tables for multilaterals, it receives one point for each table. ${ }^{6}$ The average across all tables is taken to construct an overall OECD reporting transparency index ranging from zero to one, with one implying full reporting.

In addition to OECD reporting, we undertake our own inquiries contacting the agencies directly regarding overhead costs. We attempt to collect data on permanent international staff, administrative expenses, salaries and benefits, and total development assistance disbursed. In an ideal world, it would be possible to gather more detailed information regarding overhead costs such as the number of consultants and local staff, 
but as discovered by Easterly and Pfutze (2008) these detailed inquiries are often unfruitful. We follow the same lowered ambitions of the earlier study. Therefore, we have chosen to collect data on four broad areas of overhead costs in hopes of obtaining the most consistent data. ${ }^{7}$

These inquiries are taken in multiple stages. The first stage involves consulting each agencies website to find the four numbers, including going through the latest annual reports available. If data are available directly from an agency's website, it receives one point for that particular category, otherwise it receives a zero.

The second stage follows an interactive approach introduced by Easterly and Pfutze (2008). It entails emailing all the agencies individually requesting data on all four components of operating expenses. For consistency purposes, we used the contact email address listed on each agency's website as the initial point of communication. ${ }^{8}$ The agencies were informed that they had three weeks to respond. At the end of the three weeks, a second round of emails were sent out as a reminder. They had an additional three weeks to respond with the requested information, for a total of six weeks. If an agency had any part of the information available online but did not respond to the email requests, their scores are not affected (they still receive a one in that category); however, if the information is not online but an agency replied with the requested data, they receive half a point instead of a zero in that category. Although this interactive approach is certainly not free of pitfalls, it introduces a novel direct measurement of agency responsiveness to outside observers.

Out of the 53 agencies emailed, 21 responded, 13 of the 31 bilateral agencies and 8 out of the 22 multilateral agencies. This number includes all automated responses, and 
responses with full, partial or no information. Out of the 21 responses, 13 agencies

responded before the end of the first round while 8 responded by the end of the second deadline. To create the transparency overhead costs index, the average across all four categories is calculated. Since these inquiries are done at the individual agency level, the scores are aggregated using a weighted average based on ODA disbursements to create a score by country. ${ }^{9}$ We recognize that the data may not be perfectly comparable across all agencies, but take the standard benchmark that at minimum the information should be available after inquiry; therefore, an average score below 0.5 indicates a severe lack of transparency.

\section{TABLE 2 INSERTED HERE}

Table 2 above summarizes the average transparency score across the different agencies. The raw data for the transparency indices is provided in Appendix 1. The first transparency index is based on 2008 OECD reporting as described above. All bilateral agencies fully report to all five OECD tables. Most multilaterals do some reporting but with much more variance. Eight agencies, listed above, fully report, two report $67 \%$ of the times. Only one UN agency (IFAD) fully reports (and it will also score a 1 overall on transparency). According to the OECD reporting index averages, the bilateral agencies fare better than the multilateral agencies and both are more transparent than the UN agencies.

The second index, overhead costs, gives a somewhat of a different perspective on transparency. Of the 31 bilateral agencies, 17 have permanent international employment 
data publicly available online, 21 report administrative costs, only 12 agencies report salaries and benefits, and 22 publicly report the amount of development assistance disbursements. Three agencies responded to our emails with the information regarding employment, salaries and benefits and official development assistance, while two replied regarding administrative costs. The number of agencies not reporting any data or responding to our persistent emails ranges from 6 (regarding ODA disbursements) to 16 (regarding salaries and benefits). Overall, two agencies (MOFA Japan and France’s DgCiD) fail to report any data whatsoever - a rather surprising result for government agencies in democratic polities that have agreed to the international aid transparency process. Three other agencies fall below the 0.5 transparency benchmark: all surprisingly Scandinavian: Finland, Norway, and Sweden is also poor. Seven donor agencies barely met these criteria with an average right at 0.5 , and only 4 bilateral donors fully report across all four components. Despite the rhetoric cited above, most bilaterals are surprisingly negligent reporting elementary data on their operations.

The multilateral agencies perform better than the bilateral agencies on making non-OECD DAC data publicly available. Only 1 agency fails to report any data (GEF) and only one other is at 0.5 or below. The UN agencies again perform the worst. UNDP is the most remarkable example of zero reporting, given its high profile as the UN's primary development agency.

The average index is comprised of the average across the overhead costs index and the OECD reporting index for an overall transparency score. Finally, an overall rank is applied to each agency based on their average score. Five bilaterals get a perfect score on transparency, including the UK and US,${ }^{10}$, four multilaterals, and one UN agency. 
FAO, UNDP, UNTA, and UNIFEM, all UN agencies, perform the poorest falling below the (weak) transparency benchmark.

In sum, transparency is still shockingly poor in most aid agencies. Comparing across bilateral aid agencies, the Scandinavian agencies do surprisingly poorly on this dimension. Comparing across multilateral agencies, many of the UN agencies have an extremely bad record on transparency, confirming the prior that the UN agencies are among the least accountable aid agencies.

\section{(b) Overhead Costs}

Most agencies agree that extreme overhead costs should be avoided (for example, see IMF and World Bank 2005, p. 171). Although there is not an established benchmark as to how much aid could be spent on overhead, spending a large percent of the budget on overhead could be interpreted as diversion of aid funds to sustain bureaucracy rather than deliver funds to the intended recipients. However, the optimal overhead ratio is not zero either, as a well-managed aid effort requires funding of management activities such as fiduciary oversight, monitoring and evaluation, and project design and implementation. Also, agencies vary widely in purpose and mission, and some missions may require higher administrative budgets than others.

A few of these differences we can address in our measure. For example, development banks combine aid with non-concessional loans as part of their mission. To partly account for these differences, we consider costs ratios relative to official development financing (i.e. including non-concessional loans) for multilaterals (and the UN agencies). We still use official development assistance for the bilateral donors. ${ }^{11}$ 
Also, in more recent years multilaterals have a greater role in managing things for other agencies (including joint efforts). For example, the World Bank is responsible for managing a large number of trust funds and is also responsible for accounting and fiduciary oversight at some financial intermediary funds, such as the Global Fund. ${ }^{12}$ In light of these considerations, we are cautious in interpreting our findings. We will primarily be looking for extreme outliers.

As noted in the previous section, transparency on overhead costs is dismal. Therefore, in order to calculate overhead costs for individual agencies, we utilize the information gathered from the transparency overhead calculations above to create three different categories of overhead cost indicators: ratio of administrative costs to official development assistance (or official development financing (ODF) for multilaterals that also do significant non-ODA activities), ratio of salaries and benefits to ODA (bilaterals) or ODF (multilaterals that include non-ODA activities), and total ODA or ODF disbursements per employee. Because missing data is such a problem, we use the old data from Easterly and Pftuze (2008) to record entries when no new data is available for the current period (indicated in bold in Appendix 2 where the underlying data is reported). ${ }^{13}$ We believe this is a good rule for all monitors of overhead costs to follow, because otherwise there would be an incentive for poorly performing agencies in one round of monitoring to stop reporting data in the next round.

This information gathering process has resulted in numbers that are likely not standardized across agencies because different agencies have different notions of what defines 'administrative costs' and number of 'permanent international employees.' 


\section{TABLE 3 INSERTED HERE}

Table 3 above presents the averages of the three overhead costs indicators for the averages of the all three indicators for bilateral agencies at the country level, multilateral agencies, and UN agencies. ${ }^{14}$ Bilaterals have lower overhead costs than multilaterals, who in turn have lower cost ratios than UN agencies. The most extreme among the latter are UNDP and UNFPA, who actually spend more on administrative costs than aid disbursements (129\% and 125\%, respectively). UNDP also ranks last across all agencies recording the highest salary/aid ratio at 100 percent. The United States has the highest administrative costs of the bilaterals, plausibly reflecting the much-noted phenomenon that Congress has imposed many earmarks and other multiple and conflicting mandates on USAID.

Our third measure is ODA disbursed divided by numbers of employees. The overall average is roughly $\$ 6$ million dollars disbursed per every aid employee. Bilateral agencies disburse more per employee than multilaterals, who in turn disburse more than UN agencies. The remarkably low outliers are a pitiful $\$ 30,000$ per employee for the World Food Program, \$40,000 per employee at UNHCR, \$100,000 per employee at UNICEF, and \$190,000 per employee at UNDP.

The overall ranking shows (reported in Appendix 2 that out of the top ten agencies nine are bilateral agencies (Norway ranks first) with the bottom 6 out of ten being UN agencies (World Food Program is last).

In sum, the main result on overhead costs is that the extreme poor performers are UN agencies, with very high costs driven by salaries. A secondary result is that 
multilateral agencies have higher salaries and other overhead costs relative to lending than do bilaterals.

We suggest two plausible explanations for these patterns. The first is the structure of ownership: ownership of multilaterals is diffuse, typically with ownership shares proportional to the donor's GDP. Ownership is even more diffuse with UN agencies where every country has one vote at the UN. Diffuse ownership means that there is less effective control over salaries and other costs. For example, when the overall budget of a UN agency with $\mathrm{N}$ owners increases by $\$ 1$, and $\mathrm{N}$ is large, each country only sees a small $\$ 1 / \mathrm{N}$ increase in its spending on the agency. (Our results could also confirm common perceptions of UN agencies being partly used as patronage vehicles for UN member governments.) An interesting special case is the EC, which is technically a bilateral but obviously has diffuse ownership and indeed has a remarkably high overhead cost ratio.

The rival explanation is that, as mentioned above, multilaterals have more complex tasks and additional responsibilities that bilaterals do not have, and hence the larger budgets are NOT necessarily a sign of “bloat.” We cannot definitively resolve to what degree each of these hypotheses explains our findings, but we hope these findings will stimulate further research in this area.

(c) Specialization/Fragmentation

The effectiveness of aid is reduced when there are too many duplicating initiatives, especially at country and sector levels. 
One of the biggest complaints in aid effectiveness is the lack of donor specialization. A main tenet to make aid more effective, as outlined in the Paris Declaration (2005), encourages donors to coordinate activities as a way to minimize transaction costs. A big part of the problem is duplication of efforts, which leads to multiple reporting requirements for overstretched aid recipients. Most agree that there have been too many donors in too many countries, stretched across too many sectors or projects ([World Bank, 1998, p. 25], [Commission for Africa,2005, pp. 62, 320], [IMF and World Bank, 2005, p. 171], [IMF and World Bank, 2006, p. 62], [Knack and Rahman, 2007], [Easterly, 2007] and [Frot and Santiso, 2009]). In rich countries, government bureaucracies tend to specialize more as a way of minimizing coordination problems (although these can still be severe in some cases), lowering overhead and transactions costs, and to improve incentives and accountability to the intended beneficiaries. $^{15}$

The caveat is that complete specialization by country or sector is not necessarily optimal either, so this measure may be ambiguous around relatively high levels of specialization across donors. In practice, however, most of our observations are at a high level of fragmentation that plausibly corresponds to suboptimal behavior.

Indeed, the overall picture of aid is one that is remarkably fragmented along many dimensions, forfeiting the gains from specialization and possibly creating confusion between both donor and recipient countries. Figure 1 illustrates how the 2008 international aid budget of $\$ 175$ billion is first split amongst many donors. There are 24 agencies that each account for less than 1 percent of the total budget (and then we will see below that these agencies are internally fragmented). Of course, it's a little tricky 
dealing with the existential problem of whether any particular small agency should renounce its existence in order improve system-wide fragmentation.

\section{INSERT FIGURE 1 HERE}

Each agency splits its budget among a large number of recipients and sectors. We measure fragmentation with Herfindahl coefficients that are used in industrial organization as a measure of market concentration (1 implies maximum concentration, 0

implies maximum fragmentation). ${ }^{16}$ Appendix 3 presents the 2008 country and sector Herfindahls for bilateral and multilateral agencies with an overall rank based on the average percent rank of the two indices. Table 4 below presents the summary of this data.

The World Bank and IMF’s Global Monitoring Report (2010, p. 131) states: Reducing fragmentation and strengthening aid coordination is essential to enhancing aid effectiveness. When aid comes in too many small slices from too many donors, transaction costs go up and recipient countries have difficulty managing their own development agenda. In 2006, 38 recipient countries each received assistance from 25 or more DAC and multilateral donors. In 24 of these countries, 15 or more donors collectively provided less than 10 percent of that country's total aid. The number of aid agencies has also grown enormously, with about 225 bilateral and 242 multilateral agencies funding more than 35,000 activities each year. A recent OECD survey revealed that in 2007 there were 15,229 donor missions to 54 countries - more than 800 to Vietnam alone. 
Unfortunately, the IMF (0.14) and the World Bank (0.04) themselves continue to fragment aid among many countries despite this statement.

\section{TABLE 4 INSERTED HERE}

The overall average Herfindahl by country is 0.08 and 0.20 by sector. UNRWA is at the top of specialization by country (0.43) while the rest of the UN agencies rank at the bottom. Specialization for UNRWA is a special case as it has a very specific mission (Palestinian refugees) that is concentrated regionally (see Table 1 above). Regional development banks have somewhat higher country Herfindahls, which also follows naturally from the restriction of their mission to a particular set of countries rather than the whole developing world.

Similarly, some agencies are specialized by design by sector. UNFPA has 100 percent concentration in population/reproductive health, WFP has 75 percent of its aid categorized as food aid, while the Global Fund and UNAIDS are both above 50 percent. Among other multilaterals, the Nordic Development Fund is also specialized (giving grants for climate change) and shows a high sector Herfindahl.

For the bilateral agencies, which do not have a specialized mission, fragmentation is rampant, with very low Herfindahls for both country and sector. ${ }^{17}$

To explain the fragmentation patterns, we consider two alternative hypotheses. The first is based on the idea that each new sector and each new country that a donor enters has some overhead costs regardless of scale. Therefore, we would expect smaller agencies to specialize more, while larger agencies can afford to specialize less. The 
alternative hypothesis is based on political economy: all agencies regardless of scale are subject to sector and country lobbies, and so all agencies would try to placate these lobbies with allocations to a large number of countries and sectors. Agencies also like to maximize visibility of their efforts to their political sponsors, with each additional country and sector making agency efforts more visible.

Figures 2 and 3 show the scatter between country (sector) Herfindahls and the log of aid given by each agency. Most of the variation is explained by the above mentioned outliers that are based on agency mission definition or on unusual one-time flukes (Austria and Italy_-see footnote 16).

INSERT FIGURE 2 HERE

INSERT FIGURE 3 HERE

These well-explained outliers aside, there is little sign of any association between total ODA disbursements (log) and specialization by country or sector. (Because of the 
small sample and the outliers, we do not regard any formal regressions as very informative - in any case we found no robust and significant associations between scale and specialization). For example, Belgium, Ireland, Switzerland, New Zealand, and Luxembourg are small aid givers, yet are still very fragmented by country and by sector. Luxembourg has the same country fragmentation as the US, and slightly more sector fragmentation, even though the US aid budget is 70 times larger.

If fixed startup costs by country and sector are important at all, then a lot of small donors may be having much or all of their aid eaten up by these fixed costs. These do not correspond to the overhead costs we discussed above, as this kind of startup cost is aid spending within the country or sector.

However, we would still expect overhead to be higher with fragmentation, especially in small agencies. We tested this by regressing for all agencies the overhead cost percentile ranking score (as described above) on fragmentation indices, controlling for log of ODA by agency. We did not find country fragmentation to be significant, but sector fragmentation did show a significant relationship in the predicted direction (controlling for scale of aid). The magnitude was economically meaningful - a move from complete sector fragmentation to complete specialization would raise the ranking on (having the lowest) overhead costs by 43 percentile points. ${ }^{18}$ This is some indication that fragmentation is costly for the efficient delivery of aid, although subject to the usual caveats about causality and the small sample size.

So there are many indications that donors are very far from efficient behavior on specialization. We are left with the alternative hypothesis that donors are responding to political economy incentives in fragmenting aid, a hypothesis that has long been popular 
among aid observers. As the World Bank’s landmark Assessing Aid (1998, p. 26) put it: donors like to "plant their flags" on as many countries, sectors, and projects as possible. Sadly, recent reform efforts have made no progress in reversing this behavior.

\section{(d) Selectivity}

Effective and efficient use of development financing requires both donors and partner countries to do their utmost to fight corruption.

Accra Agenda for Action (2008, page 20).

Another best practice emphasized by the Paris Declaration (2005), IMF and World Bank (2005, p. 171), and the High Level Forum (2008), is selectivity. These statements posit that aid is more effective at reducing poverty when it goes (1) to those countries in most need of it (the poorest countries) and (2) to countries with democratically accountable governments, and (3) less corrupt governments. Of course, the poorest countries are more likely to be authoritarian and corrupt, so agencies must strike a balance between supporting the poorest countries and supporting those with the best governance.

To measure overall selectivity by donor, we calculate the share of aid going to low-income countries, free countries (based on democracy scores), and less corrupt governments. We create an overall composite selectivity score where donors get positive weight on aiding poor countries and negative weight on supporting corrupt or unfree

countries. ${ }^{19}$ Appendix 4 reports the 2008 shares of aid going to noncorrupt countries, free 
countries, low-income countries, and the overall composite rank for each donor. Table 5 summarizes the results.

\section{INSERT TABLE 5 HERE}

We classify countries as free if they receive a democracy score equal to 8, 9, or 10 according to Polity IV's 0 to 10 point democracy ranking, where 0 represents autocracy and 10 fully democratic. Polity IV creates an institutionalized democracy ranking (coded as DEMOC in Polity IV's data) based on three components. This includes the competitiveness of political participation, the openness and competitiveness of executive recruitment, and the constraints placed on the chief executive. Therefore, this variable captures the extent in which citizens feel secure to express their political preferences and actively participate in the political process, as well as measures the formal rules in place to constrain executive power. Polity IV is one of the most commonly used datasets to measure democracy in the academic literature (for example, see [Marshall and Jaggers, 2004], [Persson and Tabellini, 2006] and [Acemoglu, Johnson, Robinson, and Yared 2008]).

There are of course other democracy measures. Freedom House ranks countries based on political freedom by administering an annual survey to individuals in order to access their ability to freely participate in the political process. There are pluses and minuses with this measure - it is perceived by many as ideologically biased, but it seems to capture a broader definition of democratic "freedom” than Polity. Because of concerns 
about the bias, we chose to use Polity, but in any case our results turn out to be broadly similar for the Freedom House measure.

Corruption shares are based on International Country Risk Guide’s political risk index, which has a corruption component dating back to 1984. We define corruption as a score of less than two on a zero to six-point scale. The low-income share is the sum of aid flowing to least developed countries plus other low income countries, as defined by OECD. We should note that neither Polity IV nor ICRG rank every aid receiving country, particularly lacking data for most Caribbean countries. In order to not bias the results for the Caribbean Development Bank, we supplement aid shares for Caribank with two additional data sources. ${ }^{20}$

Figure 4 plots the shares of aid to free and clean countries and to low income countries as a way to illustrate which donors are actually more selective. The top right quadrant is the most desirable as indicating successful selectivity both on poverty and on governance. The World Bank (IDA), Asian Development Bank (AsDF), and Global Fund are in this quadrant. The World Bank receives the top score on selectivity, mainly reflecting its success at directing aid to "non-corrupt” poor countries.

The off-diagonal quadrants indicate success at one dimension at the expense of the other. UNDP and UNICEF, for example, focus mainly on income as a selection criterion and do poorly on governance. At the other extreme, those donors in the bottom right quadrant - Japan and CarDB, for example -- allocate aid to well-governed countries without much consideration of income. The bottom left quadrant is the worse, indicating that poor selectivity on one dimension is NOT explained by strong selectivity on the 
other - these donors do badly on BOTH. These are the donors that have low scores on selectivity in our methodology.

\section{INSERT FIGURE 4 HERE}

The UN agencies do not do as badly on selectivity overall as on some other criteria. Rather they tend to emphasize poverty selectivity more than governance selectivity.

In contrast, the worst performers (in the lower left hand quadrant) include two major Scandinavian donors - Sweden and Norway-- that have a strikingly high tolerance for non-democratic recipients, perhaps reflecting the tradition of Scandinavian aid going to more ideologically socialist regimes that perform badly on democracy measures. The USA is the largest donor in this unsavory quadrant, perhaps reflecting the primacy of foreign policy objectives rather than aid selectivity in a superpower. ${ }^{21}$

Regional restrictions for development banks also matter -- the EBRD is stuck with relatively well off but corrupt and authoritarian clients in its region, CarDB and IDB have relatively democratic middle income countries as clients, while AfDB has poor, corrupt, undemocratic countries.

The analysis in Figure 4 is relative. The horizontal axis in Figure 4 on governance is so truncated that a large share of aid is going to badly governed countries from ALL agencies.

On average, twenty-four percent of aid flowed to free countries in 2008, and forty percent to non-corrupt countries without much variation across bilateral, multilateral or 
UN donors. For all agencies, the average share of aid flowing to low-income countries is 45 percent; here, bilaterals had a lower average share of low income countries than multilaterals and UN agencies. This may reflect greater success of the "poverty agenda" in international organizations than in bilaterals, who often have traditional ties to certain countries for historical reasons.

(e) Ineffective Channels

Untying aid generally increases aid effectiveness by reducing transaction costs for partner countries and improving country ownership and alignment.

Paris Declaration on Aid Effectiveness (2005, p.5)

The last measure of best practices calculates the share of aid being allocated through ineffective channels, as described by the agencies themselves and by the academic literature (see citations in Easterly, 2007). This includes share of aid that is tied, food aid, and aid allocated as technical assistance. Tied aid is when specifies that a certain percentage of the aid that must be spent on the donor country's goods or services. Most agencies agree that allocating aid in this manner does not promote the interests in the recipient country; instead, it is used as a means to increase the donor country's exports ([IMF and World Bank, 2005, p. 172], [United Nations Development Program, 2005, p. 102] and [Commission for Africa, 2005, p. 92]).

Food aid is another form of aid that is recognized as an inefficient way to provide assistance. ${ }^{22}$ It is viewed as a way for higher income countries to shed their excess agricultural products without any concern for the local agricultural markets in the receiving country ([IMF and World Bank, 2006, pp. 7, 83] and [United Nations 
Millennium Project, 2005, p. 197]), food aid is often tied, and in kind transfers are worse than cash transfers.

Technical assistance is also seen as a way for rich countries to promote their own interests by allocating aid that must be used to hire consultants from the donor country. Not only are benefits flowing back to the donor country, but consultants hired under these circumstances often have poor incentives to respect recipients' priorities and lack essential local knowledge ([United Nations Millennium Project, 2005, pp. 196-7] and [IMF and World Bank, 2006, p. 7]). The knowledge that these three areas are less effective ways of allocating aid is not a recent development: complaints about these shortcomings go back many years.

Of course, these assumptions do not universally hold. Technical assistance can be well-done and productive in some cases. One could also envision useful food aid, or even tied aid under some circumstances. Again, we are taking the donors' own recommendations to themselves at face value - that these three channels tend to be ineffective on average.

Appendix 5 reports the share of aid that is tied, food aid or in the form of technical assistance as of 2008 and ranks agencies based on an average of the percentage ranks from all three categories. Most data is only available for bilateral agencies and only bilateral agencies do aid tying; however, one multilateral agency (IDB) reports on technical assistance and several UN agencies report either technical assistance or food aid. Therefore, these donors are included in the analysis, but we refrain from providing a summary table given the small sample of donors. Data on technical assistance from 
multilaterals, including the UN, is often unreliable. As with the case of overhead costs, we principally focus on the worst outliers.

Despite decades of criticism, the largest bilateral, the United States, still ties a quarter of its aid. Note that this is much more informative than the Easterly and Pfutze 2008 analysis of US aid tying, because as they noted the US had stopped reporting on aid tying since 1996. They mysteriously resumed reporting in 2006 on aid tying and the number here is current (2008). ${ }^{23}$

The largest donors of food aid, are not surprisingly, agricultural powerhouses: the EC, US, and Australia. These three donors are also relatively large givers of humanitarian disaster relief, and this is significantly correlated with food aid across donors (even after excluding the extreme observation of the WFP). However, we will see below that the overall long-run trend is to move away from food aid even as disaster relief keeps growing, so disaster relief is no longer a very good "excuse" for food aid. What is even more troublesome is that food aid for the US is still tied to purchases from US farmers, which causes long delays and harms local food producers during food emergencies. It would be much better to use cash to buy food from local or nearby producers to avoid these problems; however the US agricultural lobby has so far resisted change.

Italy also ties over 20 percent of their aid. Greece and Portugal tie an even larger portion of their aid (62\% and 71\%, respectively) and both provide approximately 25 percent of aid as technical assistance. Canada and Australia also give over 30 percent in technical assistance.

Two UN agencies perform poorly on this measure by the very nature of their mission. UNTA reports donating 100 percent of its aid as technical assistance and WFP 
gives 84 percent of aid as food. Neither of these statistics should be surprising given the mission of each agency, however one may still question whether agencies with such mission statements are helpful to the overall cause of effective aid.

(f) Examining correlation among components

As a final attempt to better understand agency practices, we show the pairwise correlations and their significance level for all five best practice rankings in Table 6 below for all agencies. Only one of the correlations is statistically significant, suggesting that we are capturing largely independent measures of performance in our exercise.

The significant correlation is between transparency and low overhead. A possible explanation for this finding is that agencies with high overheads would like to conceal them. Of course, correlation does not imply causality and there are other possible explanations. Transparency and overheads may reflect some third factor driving both for example, the UN governance structure may have particular impact on these two dimensions, as suggested by the UN agencies being the worst performers on these two dimensions, as discussed above.

\section{INSERT TABLE 6 HERE}

In contrast to Knack et al. 2010, we do not interpret correlations among components as an indication of coherence of the overall measure. This is because we do not conceive of our exercise as measuring one general concept of "aid quality." We believe that different agencies are subject to different political economy constraints, mission statements, and governance structures that skew performance in some areas more than others, as we 
discuss throughout this paper. So we are not surprised that different agencies will be better or worse at different things.

Also, the interesting relationships between these dimensions may require controlling for some other factor - such as our example above about how specialization was correlated with lower overhead once we control for the scale of aid.

\section{THE BEST AND THE WORST TRENDS}

In addition, to comparing agencies among themselves, we analyze agency performance (and overall aid performance) over time to check for any sign of improvement or deterioration in performance. This is possible by utilizing original data from Easterly and Pfutze's analysis conducted in 2005-2006, as well as longer time series on some variables to establish trends. ${ }^{24}$ The Paris Declaration (2005), created by the agencies themselves to emphasize (among other things) the practices we measure here, reflected a rhetorical agreement to improve. Therefore, agencies have had several years to incorporate the criticisms and suggestions not only from the academic literature, but also from the international aid community.

\section{(a) Transparency}

Are agencies becoming more transparent as they say they should? Comparing the overall averages (0.62 in EP to 0.76 in current analysis) suggests that there are signs of improvements. For example, all bilateral agencies fully report to OECD whereas before only 15 fully reported. Also, the multilateral agencies have substantially increased reporting to OECD. Both overhead costs reporting and the average transparency index receive overall improvements. Based on the average index, 7 individual agencies that previously fell below the transparency benchmark now clear the 0.5 hurdle, 3 of which 
are multilaterals and 3 UN agencies (Luxembourg, EBRD, UNFPA, UNHCR, UNAIDS, IFC, and GEF). One of the biggest improvements came from the international development bank, EBRD, now fully reporting to OECD and making all overhead costs information publicly available. ${ }^{25}$ Although they were already transparent in the original analysis, both the Netherlands (improving overhead costs) and IFAD (improving on both indices) significantly improved their transparency, now receiving perfect scores.

UNDP went in reverse, currently falling below the transparency benchmark. It does not provide any data on overhead costs and only partially reports to OECD. One speculative explanation is that previous analysis suggested poor UNDP performance and UNDP may now want to restrict the available information on its performance.

Overall improvement still leaves average performance of aid agencies as inexcusably poor on disclosure of elementary data necessary to monitor the agencies. It will be interesting to see if current international initiatives such as the International Aid Transparency Initiative, ${ }^{26}$ Publish What You Fund, ${ }^{27}$ and AidData ${ }^{28}$ will improve matters.

(b) Overhead costs

Given that the dataset is still in its infancy and is likely to be very noisy, our main priority was to check the correlation between the results in Easterly and Pfutze (2008) and those here. The correlations are reassuringly high for every component of overhead costs ( 0.56 for log of ODA per staff, 0.84 on salaries ratio to ODA, and 0.71 for overhead ratio to ODA) and for the overall composite ranking on overhead costs (correlation $=0.74)$. We decided not to attempt to interpret the outliers to these high correlations 
because we feel that we do not have enough confidence yet in the measures to assign much significance to changes.

\section{(c) Specialization}

To track specialization trends overtime and among individual agencies, we create three different Herfindahl indices based on 3 different types of shares: the shares of all gross official development assistance given by different donors, the shares of aid allocated to different recipients, and the shares of aid allocated to different sectors. ${ }^{29}$ These can be interpreted respectively as the probability that two randomly selected aid dollars will be from the same donor, to the same country (from any donor), and to the same sector (from any donor). For fragmentation of aid by recipient and by sector, we show the median for all donors as well as the aggregates for all ODA. ${ }^{30}$

Figure 5 below illustrates the decline in specialization since 1967. Aid has become more fragmented among many donors as new donors have emerged and there was a shift away from the traditionally largest donors (US and World Bank) towards the rest.

The sharp long run decline towards greater aid fragmentation by sector is plausibly explained by the rise of the international NGOs, many of whom specialized in particular sectors and thus became potent lobbies for "their" sectors. The NGOs also campaigned for an expansion in the social sectors (health, education, clean water, etc.), which came at the expense of some traditional large sectors such as transport infrastructure and agriculture. The shift to the social sectors had already begun in the 1970s (most famously associated with World Bank President Robert McNamara) from a "growth" focus to a "poverty” focus (Easterly, 2007). There was also the effect of new 
mandates taken on by donors, as after the fall of the Berlin Wall they began in the 1990s to emphasize more democracy and corruption and to intervene more aggressively in postconflict reconstruction and "fixing failed states." Combined with new or much more emphasized issues like the environment and gender, there was a perfect storm that led sector fragmentation since the mid-1990s to be at historically unprecedented levels.

As far as aid recipient Herfindahls, the trend is also negative but not as dramatic as with sectors. The recipient fragmentation grew as aid has spread to cover virtually all regions of the world, including new ones after the fall of the Berlin Wall. There has also been an increasing emphasis on aid to Africa, which is inevitably more fragmented because of the continent's many small countries.

\section{INSERT FIGURE 5 HERE}

The Herfindhals of the typical (median) donor by sector and by recipient also trend downward. For example, in 1999 New Zealand concentrated 32 percent of its aid to postsecondary education; however, over the past nine years, New Zealand has fragmented its aid among more sectors with no sector receiving more than 12 percent in 2008, and most much less.

In the last fifteen years or so, Herfindahls have stabilized (aside from a temporary blip in 2005 due to debt relief). This may reflect simply that Herfindahls could not mathematically fall much further. Interpreted another way, they have failed to rise despite increasingly heated criticism and reform efforts (including the Paris Declaration process) 
to reduce fragmentation. This is one of the most conspicuous failures in aid practices, both in levels and in trends.

\section{(d) Selectivity}

We analyze here the trends in total aid shares going to low income countries,

corrupt governments, unfree countries, and unfree + part free countries. ${ }^{31}$ Easterly (2007) and Easterly and Pfutze (2008) both noted the lack of evidence for the conventional wisdom that donors became more sensitive to corruption and democracy after the end of the Cold War and the new emphasis on governance began in the 1990s. Easterly and Pfutze pointed out that the share of aid going to corrupt countries has actually INCREASED since the early 1990s.

\section{INSERT FIGURE 6 HERE}

This paper once again confirms and updates that finding: the share of aid flowing to corrupt countries increased from the mid-1990s through 2002 (Figure 6) and then has fluctuated around the new higher level since then. Ironically, the period of increase is the same period over which donors began to openly condemn corruption, with the rhetoric implying that aid should increasingly shift from more corrupt to less corrupt countries. We found no evidence for either a positive shift or a perverse negative shift. Instead we confirmed also the finding of Easterly and Pfutze that the increased share of aid going to corrupt countries is driven almost entirely by the increased corruption of the same aid recipients rather than by a shift from less corrupt to more corrupt countries. 


\section{INSERT FIGURE 7 HERE}

Figure 7 above tracks the share is aid of countries featuring democracy, autocracy, or something in between the two. The share of aid to democratic countries is relatively stable over the past forty years. The aid to countries classified as in-between increased over the past fifteen years, at the expense of autocrats, with the shift around the end of the Cold War. ${ }^{32}$ The 2005 blip is once again the debt relief anomaly (noted in footnotes 16 and 19), since by far the two largest recipients of debt relief (Iraq and Nigeria) were "inbetween” countries.

Analogous with corruption selectivity, we wondered how much these trends reflect donors shifting aid away from autocrats after the Cold War, as opposed to changes in autocracy among the same set of aid recipients. Figure 8 redoes Figure 7 but holding constant the country shares of aid (as of 1989) and with the actual changes in democracy.

We find a significant part of the decline in aid to autocratic regimes after 1990 is driven by changes in democracy within recipients and not changes in aid allocations. As with corruption, it is as if donors were mostly passive and did not change the shares of aid either positively or negatively in response to democratization. ${ }^{33}$

\section{INSERT FIGURE 8 HERE}

The share of low-income countries in aid trends upward in the long run (see Figure 9), but only through $1990 .{ }^{34}$ Since 1990, the share of least developed countries and other low income countries has been fluctuating around a constant level (both 
statements update and confirm findings of Easterly [2007]). This also seems to contradict aid rhetoric that calls for an increased “poverty selectivity” (e.g. Collier and Dollar, 2002)

\section{FIGURE 9 INSERTED HERE}

The bottom line is aid agency efforts on improving selectivity appears to play little role in changing selectivity outcomes, compared to changing poverty and governance in the countries that agencies have already decided to give aid for other reasons. Hence, selectivity gives another glaring contrast between recent aid agency rhetoric and actual performance.

(e) Ineffective channels

Overall, the international community has significantly decreased the amount of tied aid, food aid, and technical assistance, with the biggest improvement being recorded in the tying status of aid (Figure 10). As noted above, this figure and trend is more reliable than the one given in earlier work such as Easterly (2007), since the US has now resumed reporting aid tying (the last observation had been in 1996 at 72\%, there was no data for 1997-2005, and it then resumed at 37\% in 2006, further decreasing to 25 percent by 2008).

The share of technical assistance decreased in the new millennium. The biggest change in technical assistance came from the United States decreasing its share of aid for technical assistance from 36 percent to 2.6 percent. However, when we checked with USAID for the details of what had happened, we found this was simply a statistical change in classification and not a real change, once again illustrating how infuriatingly casual is aid reporting to the OECD DAC database. When we exclude the US from the 
above numbers (available upon request), we find that there is still a decline in technical assistance but more modest, and we worry about other similar classification problems in other donors. Hence, we cannot assert a trend in technical assistance with much confidence.

Food aid has a more obvious downward trend, from 9 to 1 percent of aid. This happened at the same time as a large increase in the share of humanitarian aid (from 0.7 percent in 1979 to 6.3 percent in 2008). Hence, it seems that donors are embracing the idea that food aid is not good practice even for humanitarian aid, where (as discussed above) cash transfers are usually more efficient and beneficial.

Combining the reduction in tied aid and food aid highlights decreased use of ineffective channels as one of the most positive trends in aid practices; it updates and confirms the similar positive trend that was already noted in Easterly (2007) and Easterly and Pfutze (2008).

\section{INSERT FIGURE 10 HERE}

Given the problems with noisy measures of overheads cited above (not to mention noisy measures of the other components), we chose not to put an emphasis on changes in relative performance by agency between Easterly and Pfutze (2008) and this exercise. Again our main priority is to check that there is a signal amidst all the noise. We found a significant correlation of 0.43 across all agencies between the earlier study and this one.

\section{OVERALL BEST AND WORST DONOR TRENDS}


Based on the five best practice measures, we give an overall ranking to all donors calculated by averaging across the percentile rankings of each individual category. When data is missing, the calculation is performed over those categories with data. In addition to separating donors into bilateral, multilateral, and UN agencies, we also separate out donors that are classified as regional banks, non-aid disbursing donors, and donors with insufficient data as an attempt to compare agencies with the similar missions and activities. Appendix 7 reports our 'main’ list of donors (including bilateral, multilateral, and UN agencies) and also ranks those agencies classified as other donors, agencies defined as regional banks, donors involved with non-aid disbursements, or agencies with insufficient data.

\section{(a) Best and Worst Donors}

Table 7 below summarizes our best and worst agencies based on our standard categories, for which we also report average scores.

For the overall scores, we confirm earlier patterns: the UN agencies on average are worse than the other multilateral agencies and the bilateral agencies, and the differences are statistically significant. In addition to the usual equality of averages test, we also conduct a simple binomial test of how likely each category is to be in the bottom half of the rankings. The test confirms that the UN is below the median at the $2 \%$ significance level; other multilaterals just fail to reach significance for being above the median of the whole sample at the $5.4 \%$ significance level (8 out of 10 were in the top half); bilaterals are evenly split. The UN agencies' overall score reflects their extremely poor performance on overhead and transparency (both significantly worse than average using the binomial test). The multilaterals' better performance reflects consistent 
(although not significant) performance slightly above average on all indicators. The bilaterals are not significantly different overall on the binomial test, although interestingly enough they are significantly worse on specialization.

These patterns are roughly in accord in common perceptions - that (1) the UN is relatively spendthrift and unaccountable, partly predicted by its very diffuse ownership, (2) the bilaterals' differential failing is their "plant the flag" syndrome that causes excessive aid fragmentation, and (3) the multilaterals' less diffuse ownership than the UN agencies correctly predicts better performance than the latter.

To pick up on another theme, the Scandinavian donors appear to be average to mediocre on the overall ranking. All four are below average on specialization and transparency. Apparently, the reputation of Scandinavia as altruistic is based on the volume of its aid, and not on following best practices in aid giving.

Finally, we look at extremes. A top rated agency among multilaterals (as well as among all categories) is the Global Fund. (We will not have much to say about the even more highly rated Nordic Development Fund, a marginal and even more specialized agency -- grant financing for climate change projects.) Global Fund scores high on transparency listing all basic information on staffing and its budget on its website. It disperses over \$5 million aid dollars per employee supporting lower overhead costs. Global Fund's aid is highly specialized by sector (by design), dispersing almost 40 percent for basic health and 60 percent to population programs. It is one of the most selective donors by choosing low income, less corrupt recipients.

We emphasize again that our measure only covers aid practices and NOT aid effectiveness. For example, the Global Fund could be doing a poor job achieving the best 
results possible for its aid disbursements and this would NOT be reflected in our rankings.

The top bilateral donor is the United Kingdom. According to our transparency criteria, DFID is one of ten agencies fully reporting aid flows to OECD and listing basic information such as number of staff, administrative costs, salaries and benefits and ODA budget on its website. DFID also has relatively low overhead costs, dispersing $\$ 4.4$ million aid dollars per employee and maintaining low administrative costs and salaries and benefits relative to aid disbursements (2.6\% and $1.6 \%$ respectively). DFID relies on more effective channels of aid disbursements, not tying any of its aid and dispersing relatively little food aid (1.3\%). Japan, New Zealand, and Germany also compare favorably completing the top five best agencies.

The worst bilateral agency is Hellenic Aid ran by Greece’s Development Cooperation Agency. Greece is not nearly as transparent as the other agencies. It does not report on the number of staff or its salaries and benefits, even after several rounds of emails requesting this information. Hellenic Aid scores poorly on selectivity dispersing 87 percent to corrupt countries and less than 12 percent to low income countries. Greece also disburses a large portion of aid through ineffective channels, tying 62 percent and allocating 27 percent of aid to technical assistance. Greece is not the only bilateral agency performing poorly. The bottom eight agencies among our main list of donors are all bilateral donors: the United States, Portugal, Sweden, Switzerland, Spain, Belgium, Finland and Greece. Remember that this poor performance relative to the average is all the more striking since the average behavior is itself unsatisfactory by minimum standards. 
The US does badly because of poor performance on selectivity and ineffective channels - the foreign policy needs of the US superpower and the lobbies for particular aid channels seem to dominate the politics of American aid.

\section{INSERT TABLE 7 HERE}

(b) Overall best and worst trends

The best trend overall is in ineffective channels, where the aid community has decreased disbursing aid through food aid, tied aid, and (possibly) technical assistance.

Transparency gets a weak honorable mention as showing some signs of improvement, although we have less confidence that our measures are comparable over time. When this is combined with our extremely low standards for transparency and with the emphasis that is placed on transparency from the international aid community, it is hard to find that much to celebrate on transparency.

Overhead cost data is too spotty and unreliable to make any judgment on overall improvement or worsening. The other two "best practices” are actually getting worse. . Since the late 1960s, splintering of aid among recipients, even for the smallest aid agencies, has gotten progressively worse and seems to have bottomed out only because of a mathematical lower bound. Since 1980, aid has continued to become more fragmented and allocated across an increasing number of sectors. Despite all the rhetoric about reducing fragmentation and improving coordination, there is no sign whatsoever in the data about any reversal of these counterproductive practices.

A good candidate for worst trend in aid is selectivity, most specifically aid to corrupt countries (see Figure 6 above). We showed that any changes in aid shares to corrupt countries are mainly due to changes in country classification, not to any responses 
from the donors, yet the donors had the option to switch to less corrupt countries and failed to do so. The corruption outcome reflects the sharpest contradiction between (a large amount of) rhetoric and symbolic actions (more anti-corruption units in recipient governments!), on one hand, and actual outcomes, on the other hand.

\section{CONCLUSION}

This study attempts to measure if donors follow best practices, as outlined in the Paris Declaration, aid agency documents, and the academic literature, and if agency behavior is improving. The general answer is no and no, with the exceptions noted above.

Above all, we recognize that the disappointing outcomes on transparency imply that much better data is needed to gain a more accurate description of the state of aid and aid agencies. This study repeats the paradoxical complaint of Easterly and Pfutze (2008): the aid data is of extremely poor quality and coverage, and what data is available shows very poor practices. Both are signs of a fundamental lack of accountability of the official aid system to any kind of independent monitoring.

We hope this is the last paper we have to do with the unsatisfactory OECD DAC database, and that the new Aid Data exercise now becoming available will make possible a deeper understanding of aid agency behavior. However, there will still likely be an important role for the OECD DAC as an official enforcer and standardized data collector for OECD members and multilaterals that have already supposedly agreed to its requirements and standards. However, the OECD DAC in this paper shows poor enforcement and low quality standards, and so would itself need major reform.

At the same time, we are not naïve that these efforts alone will bring transparency and accountability. The political climate must pressure the aid agencies to produce 
comparable and accurate data on their operations. And it should put even more of a burden on the aid agencies is to match the reality of aid practices to their rhetoric. 
${ }^{1}$ Official Development Assistance is defined as those flows to recipients on the DAC recipient list and multilateral development institutions from official agencies granting aid to promote economic welfare and is concessional in nature with at least a $25 \%$ grant element; therefore this excludes private flows.

${ }^{2}$ For empirical studies supporting the ineffectiveness of foreign aid in achieving development, see ([Boone, 1996], [Svensson, 1999, 2000], [Knack, 2001], [Brumm, 2003], [Ovaska, 2003], [Brautigam and Knack, 2004], [Easterly et al., 2004], [Djankov, Montalvo, and Reynal-Querol, 2006, 2008], [Hartford and Klein, 2005], [Heckelman and Knack, 2008] and [Williamson, 2008]).

${ }^{3}$ AidData attempts to gather data on development financing and foreign aid at the project level providing comprehensive descriptive information across donors and time. We choose to rely on OECD DAC as our main source of data but do not suspect that our results would be significantly different if we were to use AidData (Tierney et al., 2011).

${ }^{4}$ The main database for official development assistance, OECD DAC, is substantially improved and updated since Easterly and Pfutze (2008); therefore, the results from this study are not directly comparable.

${ }^{5}$ An alternative methodology is to do numeric ranks instead of percentile ranks. These two methodologies will give different rankings when there are ties and differing sample sizes across indicators or subindicators. We did a sensitivity check of our analysis with numeric ranks and found very similar results (available on request).

${ }^{6}$ From the Creditor Reporting System (CRS), we use information based on All Commitments—All details and All Disbursements-All details. From the OECD DAC database, I use table "Total Official Flows" and for bilateral agencies only I look at table 1 (Official and Private Flows, main aggregates) and table 7b (Tying Status of Bilateral Official Development Assistance).

${ }^{7}$ Some recent criticisms of Easterly and Pfutze (2008) (for example,[ BenYishay and Wiebe, 2009]) argue that by including several measures of employment unfairly weights the index in favor of employment data 
versus the other subcomponents; therefore, we only include one broad employment measure in the transparency index.

${ }^{8}$ Often agencies would respond with a specific person to contact, in which case we would resend the initial email to that person. This is the same methodology followed by Easterly and Pfutze (2008).

${ }^{9}$ If no disbursement data is available, a simple average is used.

${ }^{10}$ The United States had a slightly less than perfect score of 0.99 (the MCC received a 0.5 for ODA data availability) but is included because it is so close to perfect.

11 We use official development financing defined as the sum of ODA plus nonconcessional loans for the multilaterals agencies because the development banks tend to support other purposes besides granting aid; therefore, to gain a more accurate description of overhead costs ODF is substituted in this analysis only.

${ }^{12}$ We are grateful to one of the referees for reminding us of the Global Fund example.

${ }^{13}$ This includes Norway, Finland, UNDP, Australia admin, Portugal staff, Italy salaries/benefts and admin, Sweden salaries/benefits, Switzerland salaries/benefits, AsDB salaries/benefits and admin, Denmark staff, UNRWA salaries/benefits, CARDB salaries/benefits.

${ }^{14}$ If an agency is missing data in a category, the average percent rank is calculated by averaging the categories where data is available.

15 The gain from specialization under a division of labor as a means of social cooperation is one of the oldest principles in economics (Smith, 1776).

${ }^{16}$ This is done by calculating the aid shares and then sum the squares of these values.

17 Two bilateral donors stand out for being much less fragmented than the others by both country and sector: Austria and Italy (see Appendix Table 4). These two countries had not been standouts in Easterly and Pfutze (2008) on fragmentation, and in fact their fragmentation outlier in our data turns out to be a fluke. They both gave a large share of their aid as debt relief to Iraq (a one-time event) in 2008, which made for high concentration both by sector (debt relief) and by country (Iraq). This episode shows the importance of monitoring performance over several years as well as carefully checking outliers. 
${ }^{18}$ Results available on request.

19 The composite score is calculated as: $0.25 \mathrm{X}$ percentile rank(share not going to corrupt countries) +0.25 $\mathrm{X}$ percentile rank(shares going to free countries) $+0.50 \mathrm{X}$ percentile rank(shares going to low income countries).

${ }^{20}$ For CariBank shares, we also use data on democracy rankings from Przeworski et al. (1997, 2000) (updated in Cheibub et al., 2010), which is a dichotomous rankings, and data on corruption rankings from Transparency International's CPI (2008). Countries receiving scores less than 3 are considered corrupt. We do so in order to not bias the rankings on CariBank due to significant missing data for most Caribbean countries.

${ }^{21}$ Other outcomes reflect quirks previously pointed out (footnote 16) - Italy and Austria do badly because of their one-time large debt relief transfer to Iraq -- a corrupt, middle income country.

${ }^{22}$ We recognize that food aid is often given for humanitarian purposes as opposed to development purposes; however, it is still viewed as an inefficient and donor driven means of providing assistance (see below).

${ }^{23}$ We have investigated the changes in USAID in reporting and non-reporting. Although we have had trouble getting a straight answer from USAID on this, one factor appears to have been a change in measurement and reporting systems within USAID after 1996, and again after 2005, so the motivation for non-reporting was not automatically political.

24 To match our current methodology, we recalculate EP’s overhead costs index from the original, averaging only across permanent international employment, administrative costs, salaries and benefits, and ODA disbursements.

${ }^{25}$ Easterly and Pfutze (2008) heavily criticized EBRD in their original analysis.

${ }^{26}$ http://www.aidtransparency.net/

${ }^{27}$ http://www.publishwhatyoufund.org/ 
${ }^{28}$ http://www.aiddata.org/home/index

29 The 36 sectoral classifications are defined by OECD and are: I.1.a. Education, Level Unspecified; I.1.b. Basic Education; I.1.c. Secondary Education; I.1.d. Post-Secondary Education; I.2.a. Health, General; I.2.b. Basic Health; I.3. Population Pol./Progr. \& Reproductive Health; I.4. Water Supply \& Sanitation; I.5.a. Government \& Civil Society-general; I.5.b. Conflict, Peace \& Security; I.6. Other Social Infrastructure \& Services; II.1. Transport \& Storage; II.2. Communications; II.3. Energy; II.4. Banking \& Financial Services; II.5. Business \& Other Services; III.1.a. Agriculture; III.1.b. Forestry; III.1.c. Fishing; III.2.a. Industry; III.2.b. Mineral Resources \& Mining; III.2.c. Construction; III.3.a. Trade Policies \& Regulations; III.3.b. Tourism; IV.1. General Environment Protection; IV.2. Other Multisector; VI.1. General Budget Support; VI.2. Dev. Food Aid/Food Security Ass.; VI.3. Other Commodity Ass.; VII. Action Relating to Debt; VIII.1. Emergency Response; VIII.2. Reconstruction Relief \& Rehabilitation; VIII.3. Disaster Prevention \& Preparedness; IX. Administrative Costs of Donors; X. Support to NGOs; XI. Refugees in Donor Countries.

${ }^{30}$ The median Herfindahl is calculated across all donors for which full data is available from 1967-2008.

${ }^{31}$ We include the median values as well as the shares of aid for all donors.

${ }^{32}$ In an earlier version of the paper, we used Freedom House classifications of "free," "unfree” and "partly free.” The results on democracies/free countries were similar. Polity IV shows more of a shift from autocracies to in-between after the end of the Cold War than does Freedom House.

${ }^{33}$ Of course, the donors' commitment to democracy would get more support if the donors get credit for inducing countries to shift away from autocracy (or other improvements in governance). We cannot address that very large issue in this paper, but the results from the literature on donors' effect on democracy do not support a positive donor role. Knack (2004) finds no association between aid and the change in democracy. Djankov, Montalvo and Reynal-Querol $(2006,2008)$ found a causal negative relationship from aid to the change in democracy. Of course, if donors got credit for an improvement in democracy, then should they also get (dis)credit for the worsening of corruption?

${ }^{34}$ These results are similar to those found in Easterly (2007) and Easterly and Pfutze (2008). 


\section{REFERENCES}

Acemoglu, D., Johnson, S., Robinson, J.A., \& Yared, P. (2008). Income and Democracy, American Economic Review, 98(3), 808-842.

AidData Database. (2010). http://www.aiddata.org

Bauer, P.T. (2000). From Subsistence to Exchange. Princeton: Princeton University

Press.

BenYishey, A. \& Wiebe, F.S. (2009). Can Aid Agencies Follow Best Practices? An

Assessment of the Millennium Challenge Corporation’s Aid Practices Based on Easterly

\& Pfutze (2008). Millennium Challenge Corporation Working Paper.

Birdsall, N., Kharas, H., \& Mahgoub, A. (2010). A Quality of Development Assistance

Index. Center for Global Development and the Wolfensohn Center for Development at the Brookings Institution.

Boone, P. (1996). Politics and the Effectiveness of Foreign Aid. European Economic

Review, 40 (2), 289-329.

Brautigam, D. \& Knack, S. (2004). Foreign Aid, Institutions and Governance in Sub-

Saharan Africa. Economic Development and Cultural Change 52 (2), 255-86.

Brumm, H.J. (2003). Aid, policies and growth: Bauer was right. Cato Journal, 23 (2), 167-74.

Center for Global Development. (2007). Measuring the Quality of Development Assistance: Discussion Draft. Washington, DC: Center for Global Development. Cheibub, J. A., Gandhi, J., \& Vreeland, J. R. (2010). Democracy and Dictatorship Revisited. Public Choice, 143 (1-2), 67-101. 
Collier, P. \& Dollar, D. (2002). Aid Allocation and Poverty Reduction. European Economic Review, 46 (8), 1475-1500.

Commission for Africa. (2005). Our Common Interest: Report of the Commission for Africa. London, UK.

Djankov, S., Montalvo, J. G., \& Reynal-Querol, M. (2006). Does Foreign Aid Help? Cato Journal, 26 (1), 1-28.

Djankov, S., Montalvo, J.G. \& Reynal-Querol, M. (2008). The curse of aid. Journal of Economic Growth, 13 (3), 169-194.

Dollar, D. \& Levin, V. (2006). The Increasing Selectivity of Foreign Aid, 1984 - 2003. World Development, 34 (12), 2034-46.

Easterly, W. (2001). The Elusive Quest for Growth: Economists’ Adventures and Misadventures in the Tropics. Cambridge, MA: MIT Press.

-----. (2006). The White Man's Burden: Why the West's Efforts to Aid the Rest Have Done So Much Ill and So Little Good. New York, NY: Penguin Press.

-----. (2007). “Are Aid Agencies Improving?” Economic Policy 22(52): 633-678.

Easterly, W., Levine, R. \& Roodman, D. (2004). New Data, New Doubts: A

Comment on Burnside and Dollar’s ‘Aid, Policies, and Growth. American

Economic Review, 94 (3), 774-780.

Easterly, W. \& Pfutze, T. (2008). Where Does the Money Go? Best and Worst Practices in Foreign Aid. Journal of Economic Perspectives, 22 (2), 29-52.

Frot, E. \& Santiso, J. (2009). Development Aid and Portfolio Funds: Trends, Volatility and Fragmentation. OECD Development Centre Working Papers \#275. 
Hartford, T. \& Klein, M. (2005). Aid and the Resource Curse. The World Bank Group No. 291.

Heckelman, J. \& Knack, S. (2008). Foreign Aid and Market-Liberalizing

Reform. Economica, 75 (299), 542-548.

IMF, and World Bank. (2005). Global Monitoring Report 2005: Millennium

Development Goals: From Consensus to Momentum. Washington, DC: World Bank. IMF, and World Bank. (2006). Global Monitoring Report 2006: Strengthening Mutual Accountability — Aid, Trade, and Governance. Washington, DC: World Bank.

IMF, and World Bank. (2010). Global Monitoring Report 2010: The MDGs after the Crisis. Washington, DC: World Bank.

International Aid Transparency Initiative. (http://www.aidtransparency.net) International Country Risk Guide. (2008). Corruption Index. The PRS Group, Syracuse, NY.

Knack, S. (2001). Aid Dependence and the Quality of Governance: Cross-Country Empirical Tests. Southern Economic Journal, 68(2), 310-29.

Knack, S. (2004). Does Foreign Aid Promote Democracy? International Studies Quarterly, 48 (1), 251-266

Knack, S. \& Rahman, A. (2007). Donor Fragmentation and Bureaucratic Quality in Aid Recipients. Journal of Development Economics, 83 (1), 176-197.

Knack, S., Rogers, F.H., \& Eubank, N. (2010). Aid Quality and Donor Rankings. World Bank Policy Research Working Paper No. 5290.

Marshall, M. G., \& Jaggers, K. (2004). Polity IV Project: political regime characteristics and transitions, 1800 - 2004 dataset users manual manuscript, Center for Global Policy 
School of Public Policy, George Mason University, Arlington, VA. Dataset available at: http://www.cidcm.umd.edu/polity.

Martens, B., Mummert, U., Murrell, P., \& Seabright, P. (2002). The Institutional Economics of Foreign Aid. Cambridge University Press.

Moyo, D. (2009). Dead Aid: Why Aid is Not Working and How There is a Better Way for Africa. NY, NY: Farrar, Straus and Giroux.

Ovaska, T. (2003). The Failure of Development Aid. Cato Journal, 23 (2), 175-88.

Persson, T. \& Tabellini, G. (2006). Democracy and development: the devil in the details. American Economic Review Papers and Proceedings, 99 (2), 319-324.

Przeworski, A. \& Limongi, F. (1997). Modernization: Theory and Facts. World Politics 49 (2), 155-183.

Przeworski, A., Alvarez, M., Cheibub, J.A., \& Limongi, F. (2000). Democracy and Development: Political Institutions and Material Well-being in the World, 1950-1990. New York, NY: Cambridge University Press.

Publish What You Fund (2010). Aid Transparency Assessment 2010. London, Publish What You Fund.

OECD (2008). 2008 Survey on Monitoring the Paris Declaration: Effective Aid by 2010? Paris, OECD

(www.oecd.org/dac/hlfsurvey <http://www.oecd.org/dac/hlfsurvey>).

OECD. (2003). 2003 Rome Declaration on Harmonization. Rome, OECD.

OECD. (2005). 2005 Paris Declaration on Aid Effectiveness. Paris, OECD.

OECD. (2008). 2008 Accra High Level Forum on Aid Effectiveness. Accra, OECD. 
OECD DAC Database.

(http://www.oecd.org/document/33/0,2340,en_2649_34447_36661793_1_1_1_1,00.html \#dac)

Roodman, D. (2006 and 2009). An Index of Donor Performance. Center for Global Development Working Paper Number 67. Data set updated 2009.

Smith, A. (1991, [1776]). The Wealth of Nations. New York, NY: Alfred A. Knopf, Everyman’s Library.

Svensson, J. (1999). Aid and Growth: Does Democracy Matter? Economics \& Politics, 11(3), 275-297.

Svensson, J. (2000). Foreign Aid and Rent-Seeking. Journal of International Economics 51:437-461.

Tierney, M.J., Nielson, D., Hawkins, D. G., Roberts, J.T., Findley, M.G., Powers, R.M., Parks, B. Wilson, S., \& Hicks, R.L. (2011). More Dollars than Sense? Addressing Knowledge Scarcity in Development Finance. World Development Journal, Special Issue.

Transparency International. (2008). Corruption Perception Index 2008. Berlin, Germany: Transparency International.

United Nations Development Program. (2005). Human Development Report 2005:

International Co- operation at a Crossroads: Aid, Trade, and Security in an Unequal World. New York, NY: United Nations Development Program.

United Nations Millennium Project. (2005). Investing in Development: A Practical Plan to Achieve the Millennium Development Goals (Main Report). United Nations: New York. 
Williamson, C. R. (2008). Foreign Aid and Human Development: The Impact of Foreign Aid to the Health Sector. Southern Economic Journal, 75(1): 188-207. World Bank. (1998). Assessing Aid. Washington D.C.: World Bank. 
Table 1: List of Multilateral and UN Agencies

Multilateral agency Description

\begin{tabular}{ll}
\hline African Dev. Bank & Africa Development Bank \\
Asian Dev. Bank & Asian Development Bank \\
CariBank & Carribean Development Bank \\
& European Bank for Reconstruction and \\
EBRD & Development \\
GEF & Global Environment Facility \\
& The Global Fund to fight AIDS, Tuberculosis, and \\
Global Fund & Malaria \\
& International Bank for Reconstruction and \\
IBRD \& IDA (World Bank) & Development (gives ODF); International \\
IDB & Development Association (gives ODA) \\
& Inter-American Development Bank \\
& International Monetary Fund (Gives aid loans \\
IMF (SAF,ESAF,PRGF) & called Structural Adjustment Facilities (SAF), \\
Nordic Dev. Fund & Extended SAF, and Poverty Reduction and \\
United Nations (UN) agency & Growth Facilities) \\
\hline IFAD (UN) & Nordic Development Fund (Gives grants for \\
UNAIDS & climate change) \\
UNDP & Description \\
UNFPA & International Fund for Agricultural Development \\
UNHCR & United Nations J oint Program on HIV/AIDS \\
UNICEF & United Nations Development Program \\
UNIFEM & United Nationsl Population Fund \\
UNRWA & United Nations High Commissioner for Refugees \\
UNTA & United Nations Children's Fund \\
WFP (UN) & United Nations Development Fund for Women \\
& United Nations Relief and Work Agency for \\
& Palestine Refugees in the Near East \\
United Nations Technical Assistance \\
World Food Program \\
\hline
\end{tabular}


Table 2: Transparency

\begin{tabular}{cc}
\hline \hline & Avg. Score \\
Bilateral Agency & \\
OECD Reporting & 1.00 \\
Overhead costs & 0.64 \\
Average Index & 0.82 \\
& \\
Multilateral Agency & \\
OECD Reporting & 0.88 \\
Overhead costs & 0.77 \\
Average Index & 0.83 \\
UN Agency & \\
OECD Reporting & 0.58 \\
Overhead costs & 0.53 \\
Average Index & 0.56 \\
All Agencies & \\
OECD Reporting & 0.87 \\
Overhead costs & 0.65 \\
Average Index & 0.76 \\
\hline
\end{tabular}


Table 3: Overhead Costs

\begin{tabular}{cc}
\hline \hline & Avg. Score \\
Bilateral Agency & \\
Admin budget / ODA or ODF & $7.60 \%$ \\
Salaries and Benefits / ODA or ODF & $4.51 \%$ \\
ODA or ODF / staff & $\$ 8.49$ \\
Multilateral Agency & \\
Admin budget / ODA or ODF & $18.18 \%$ \\
Salaries and Benefits / ODA or ODF & $7.64 \%$ \\
ODA or ODF / staff & $\$ 3.28$ \\
& \\
UN Agency & $45.57 \%$ \\
Admin budget / ODA or ODF & $45.10 \%$ \\
Salaries and Benefits / ODA or ODF & $\$ 1.22$ \\
ODA or ODF / staff & \\
All Agencies & $17.15 \%$ \\
Admin budget / ODA or ODF & $11.72 \%$ \\
Salaries and Benefits / ODA or ODF & $\$ 5.71$ \\
ODA or ODF / staff &
\end{tabular}


Figure 1: Share of Gross ODA by Donor 2008

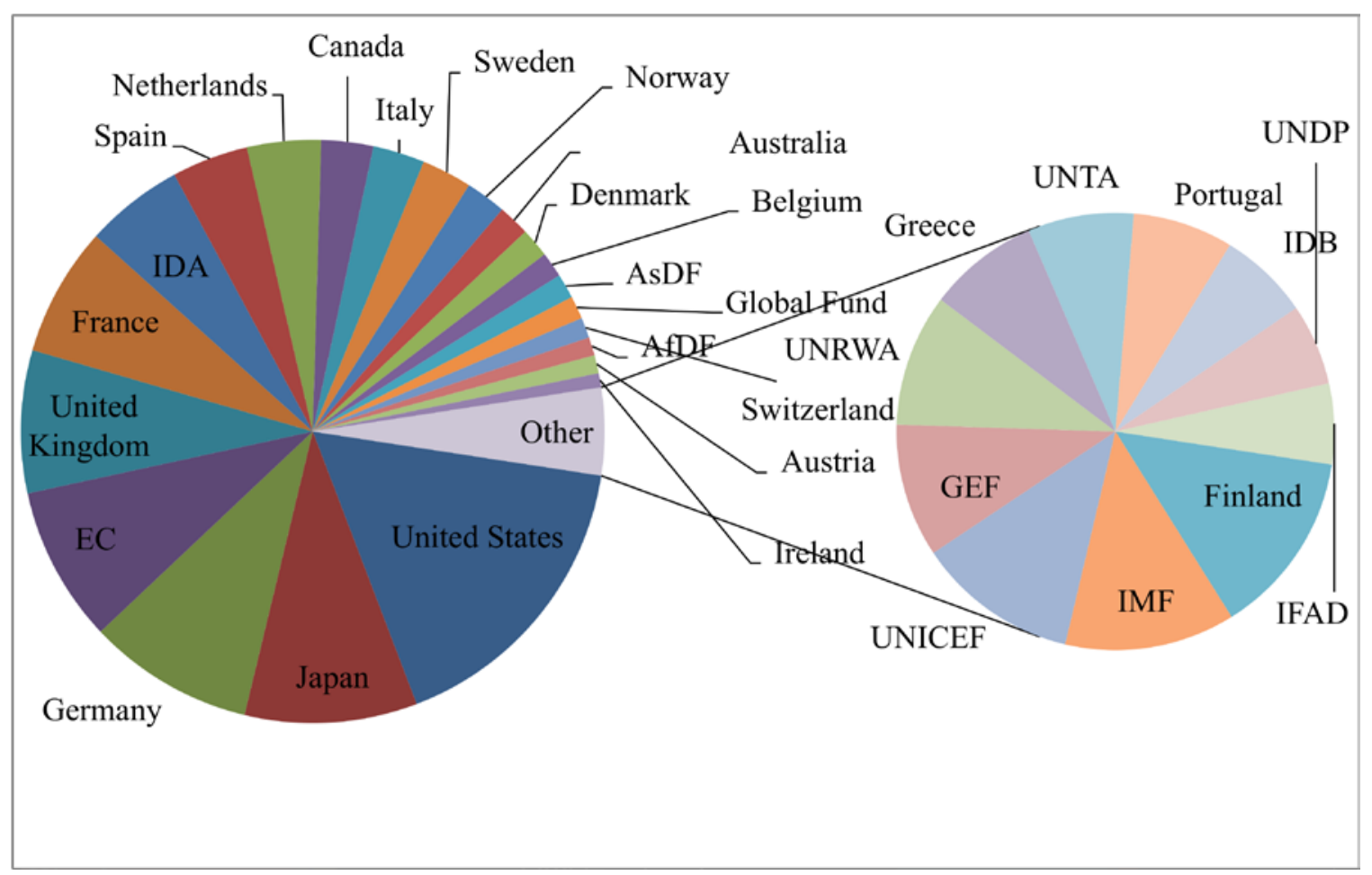

Note: Data from OECD DAC. 
Table 4: Specialization

\begin{tabular}{cc}
\hline \hline & Avg. Score \\
Bilateral Agency & \\
Country Herfindahl & 0.08 \\
Sector Herfindahl & 0.10 \\
Average Herfindahl & 0.09 \\
& \\
Multilateral Agency & \\
Country Herfindahl & 0.09 \\
Sector Herfindahl & 0.29 \\
Average Herfindahl & 0.16 \\
& \\
UN Agency & \\
Country Herfindahl & 0.07 \\
Sector Herfindahl & 0.50 \\
Average Herfindahl & 0.20 \\
& \\
All Agencies & \\
Country Herfindahl & 0.08 \\
Sector Herfindahl & 0.20 \\
Average Herfindahl & 0.13 \\
\hline
\end{tabular}


Figure 2: Country Herfindahls and Amount of Aid Given (Log) by Agency, 2008

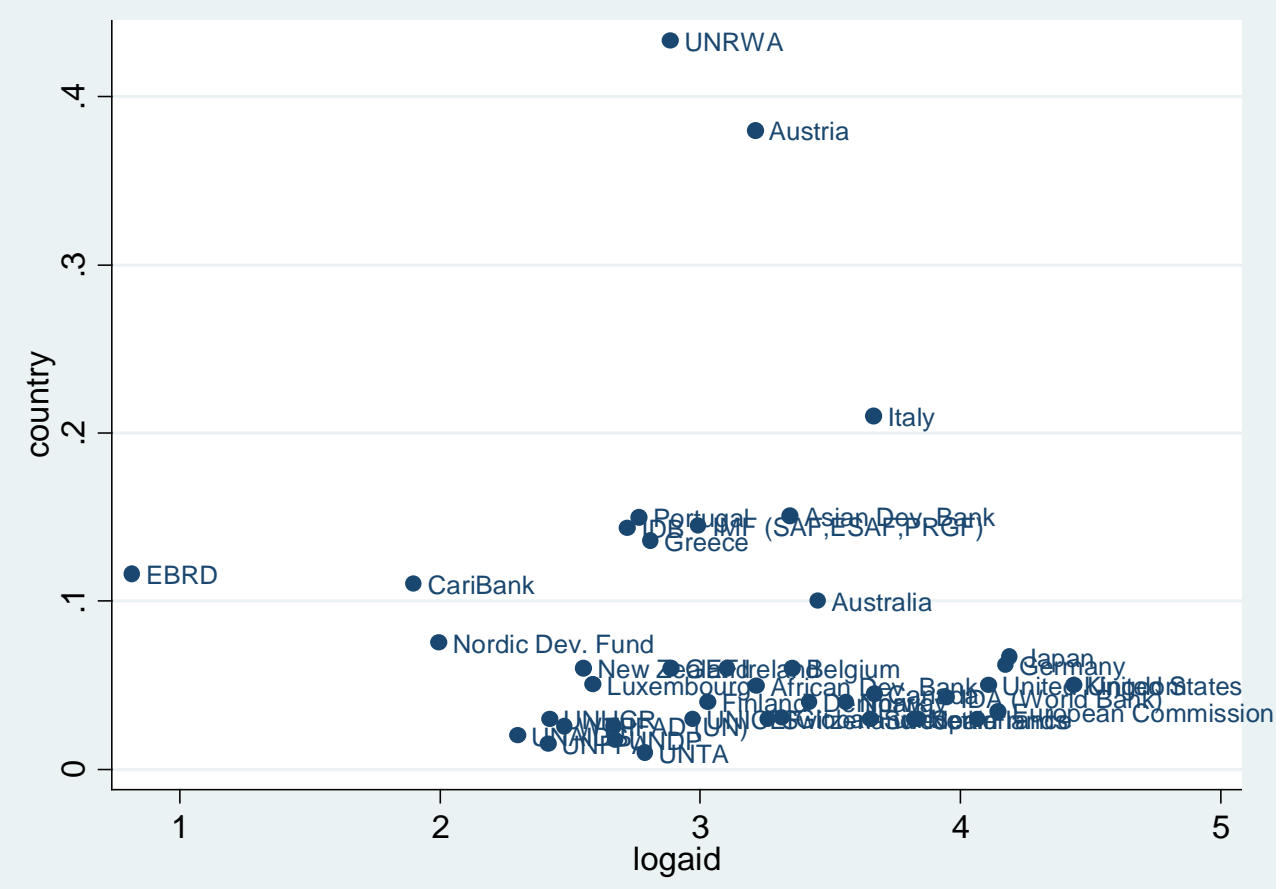

Note Data from OECD DAC. 
Figure 3: Sector Herfindahls and Amount of Aid Given (Log) by Agency, 2008

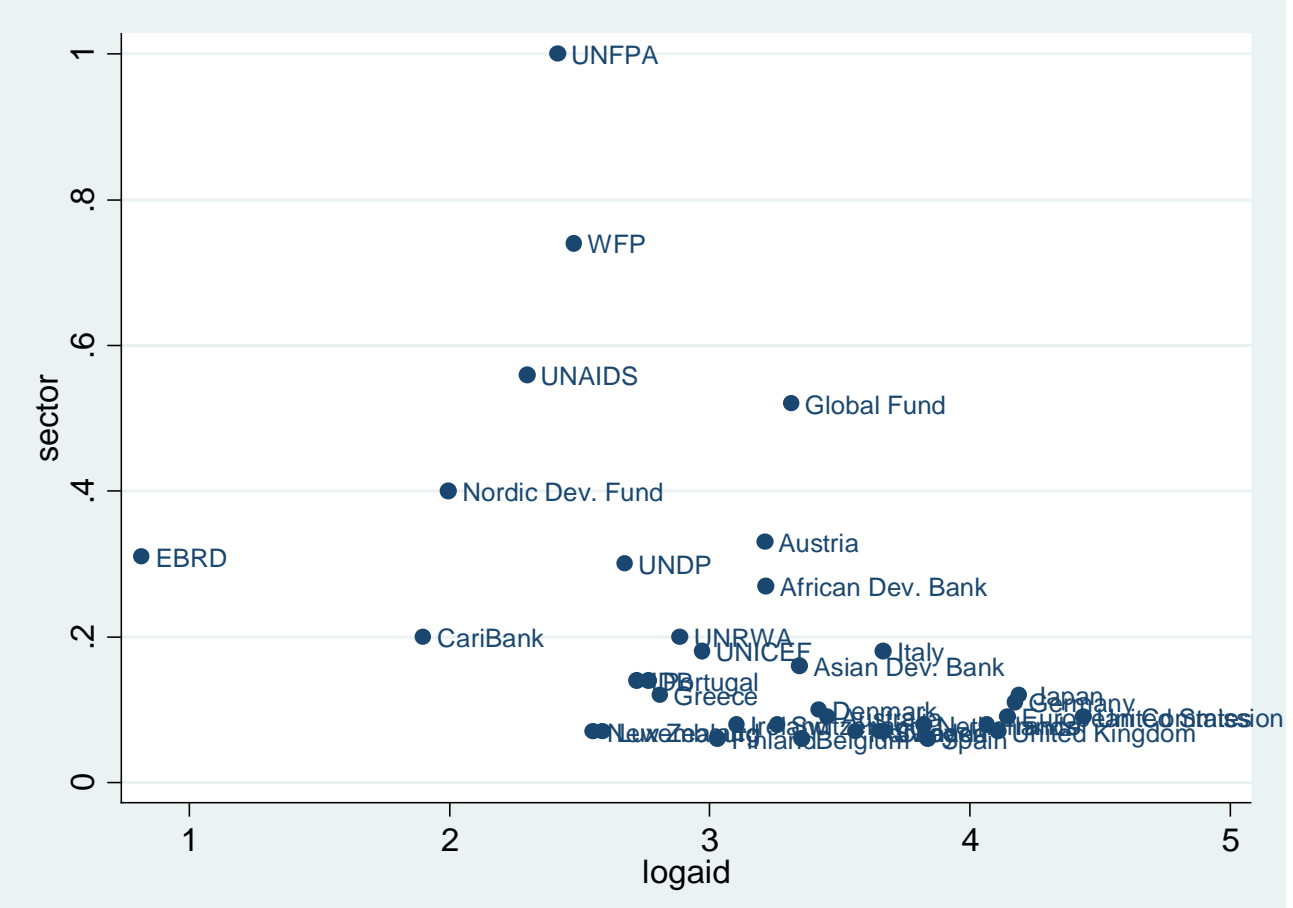

Note: Data from OECD DAC. 
Bilateral Agency

Share to Noncorrupt

Share to Free

Share to Poor

Multilateral Agency

Share to Noncorrupt

Share to Free

Share to Poor

UN Agency

Share to Noncorrupt

Share to Free

Share to Poor

\section{All Agencies}

Share to Noncorrupt Share to Free

Share to Poor
Avg. Score

$39.13 \%$

$23.32 \%$

$38.43 \%$

$41.85 \%$

$25.89 \%$

$56.57 \%$

$35.53 \%$

$21.11 \%$

$50.18 \%$

$39.01 \%$

$23.46 \%$

$45.15 \%$ 
Figure 4: Selectivity performance on governance and poverty by Agency

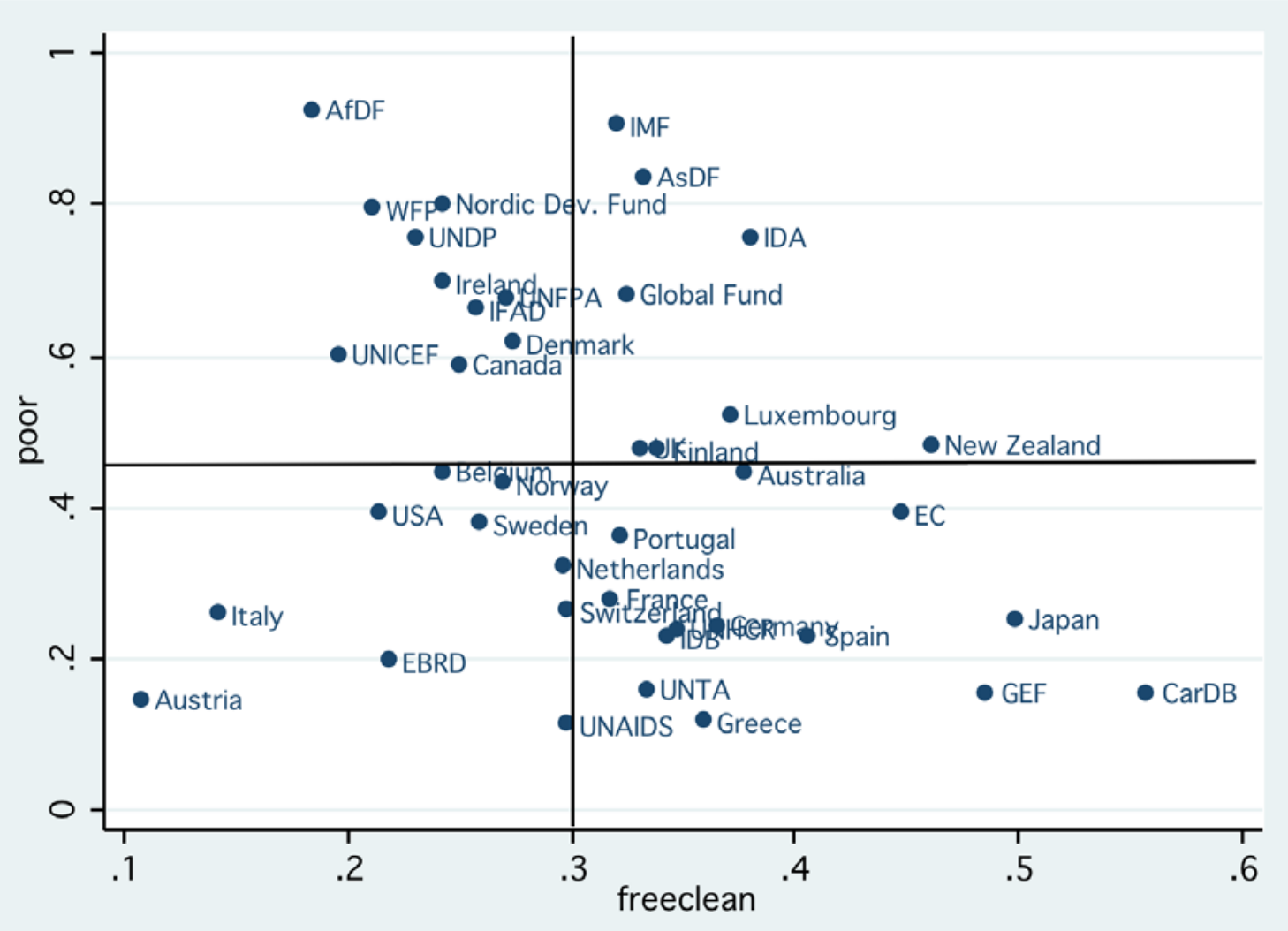

Note: The share of aid to 'Poor' represents those countries classified by OECD as least developed plus other low income. Ratio of aid to 'Freeclean' are those countries identified by Polity IV's democracy data as 'free' and by ICRG as 'not corrupt.' 
Table 6: Correlation Among Best Practices

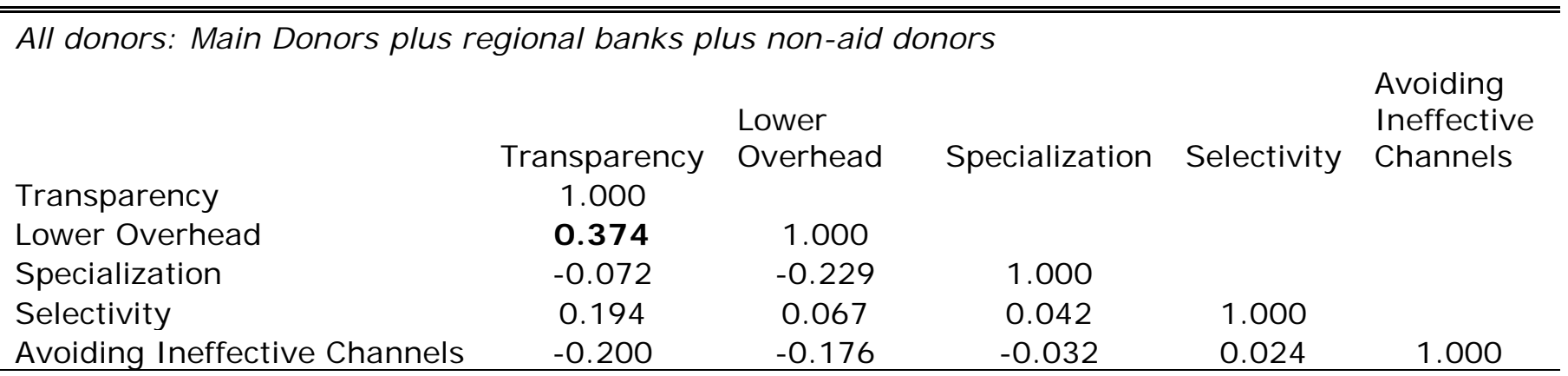

Note: Bold coefficients represent those correlations significant at the $5 \%$ level. 
Figure 5: Herfindahl Trends 1967-2008

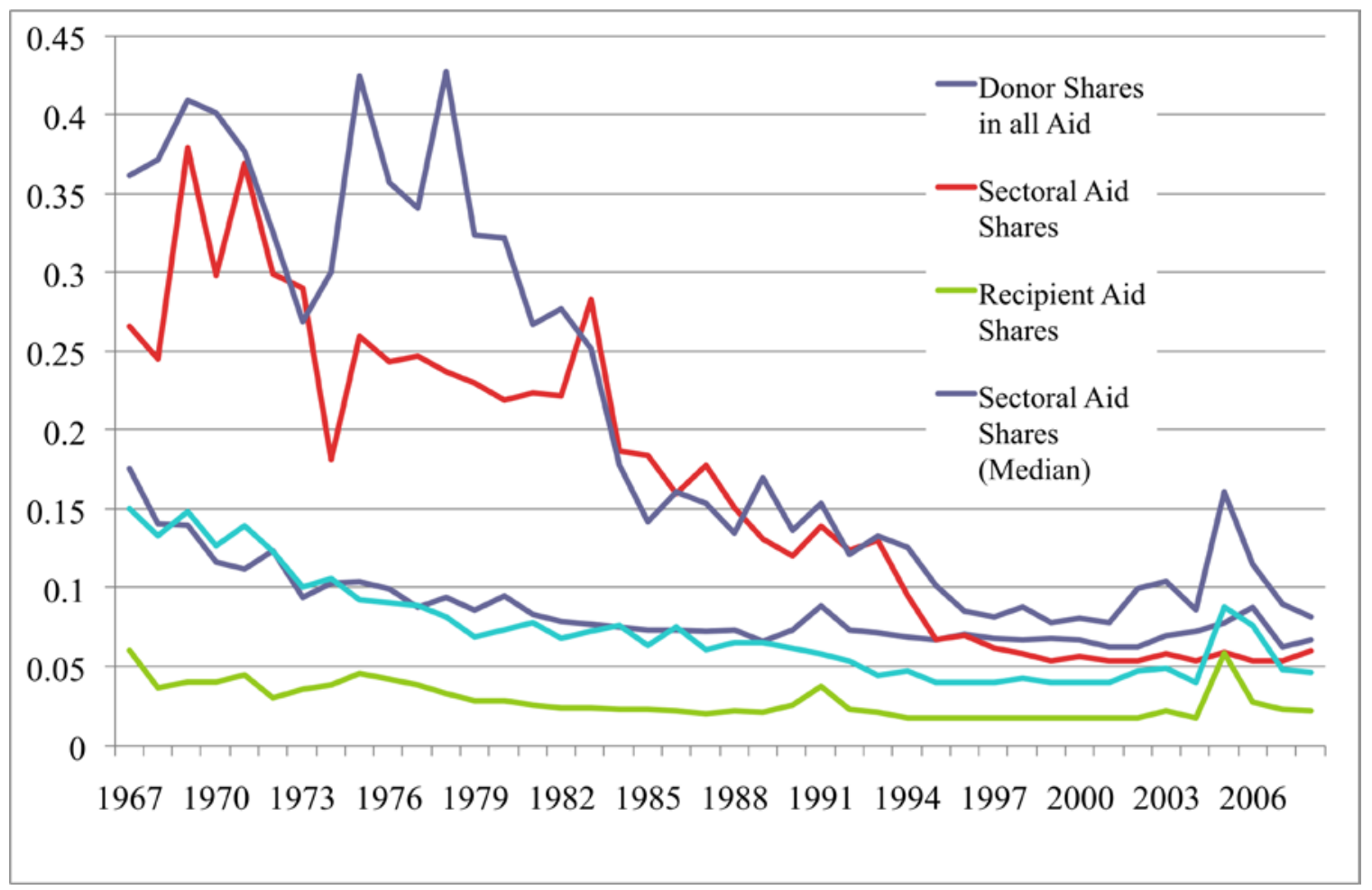

Note: Data from OECD DAC. 
Figure 6: Share of Aid to Corrupt Countries 1984-2008

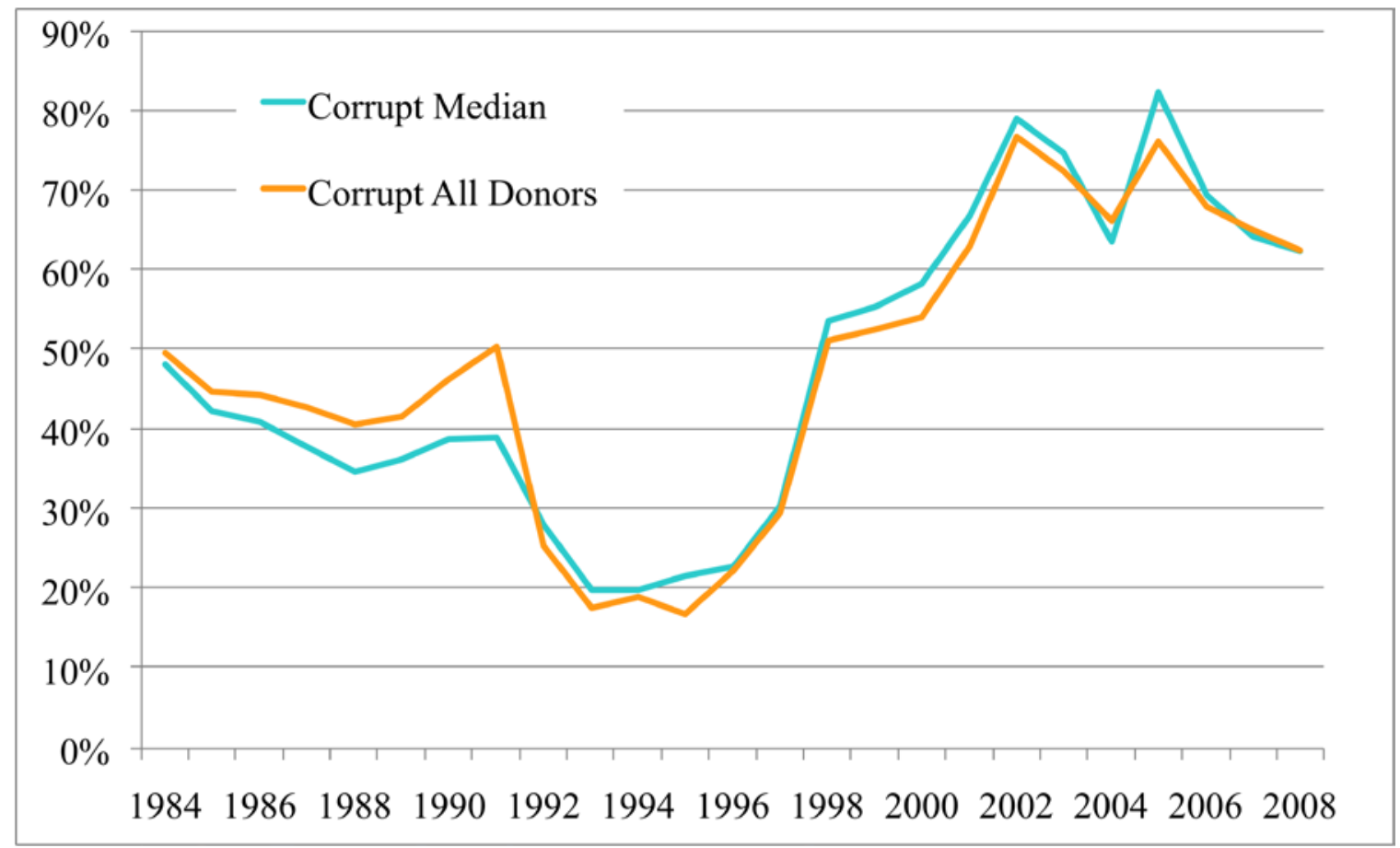

Note: Data from ICRG's corruption index. 
Figure 7: Aid Shares by Democratic Status

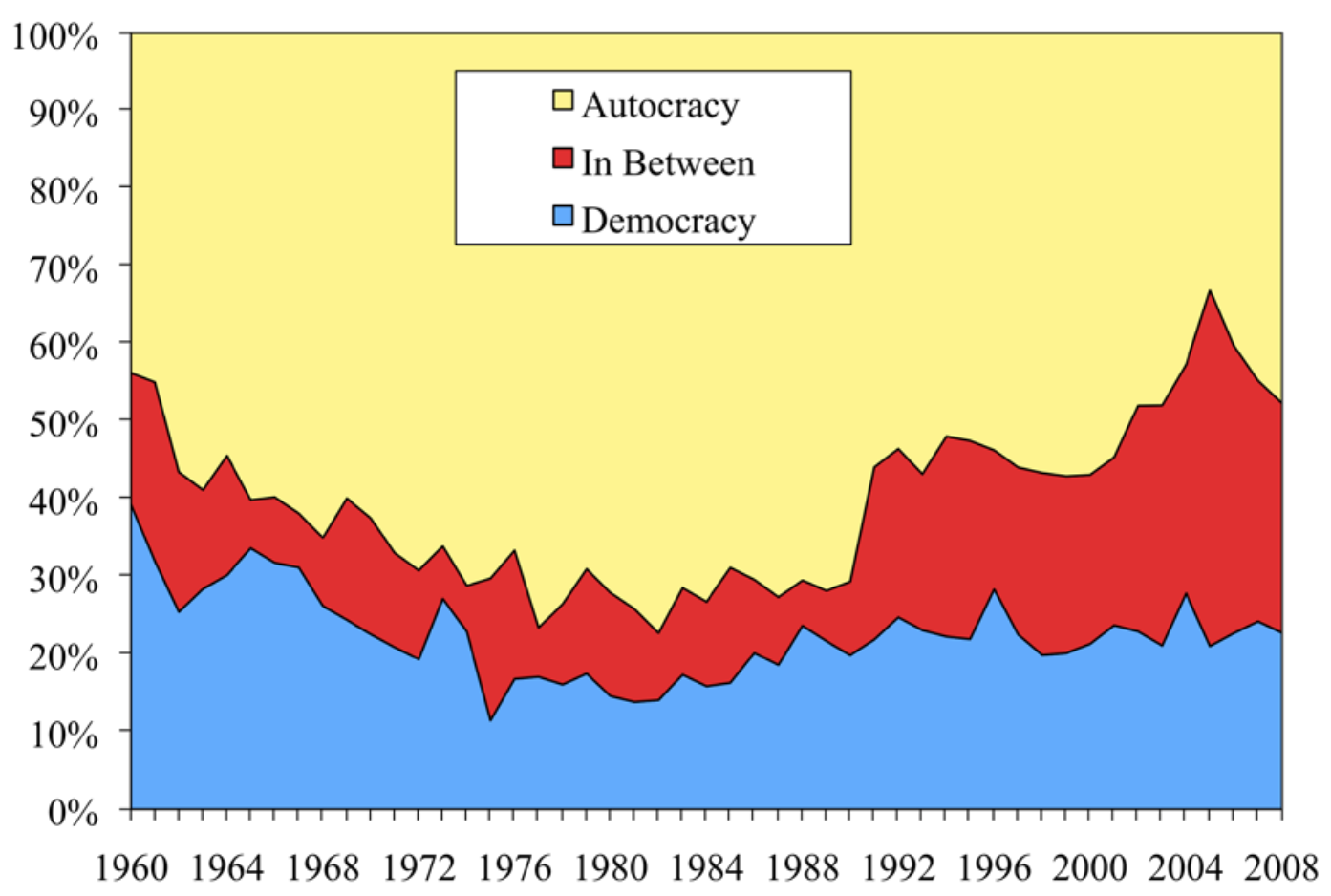

Note: Source is Polity IV. Democracy equals a score of 8, 9, or 10 from democ, autocracy equals a positive score on autoc, and in between is the rest. 
Figure 8: Aid Shares by Democratic Status if Recipient Country Shares were Unchanged from 1990

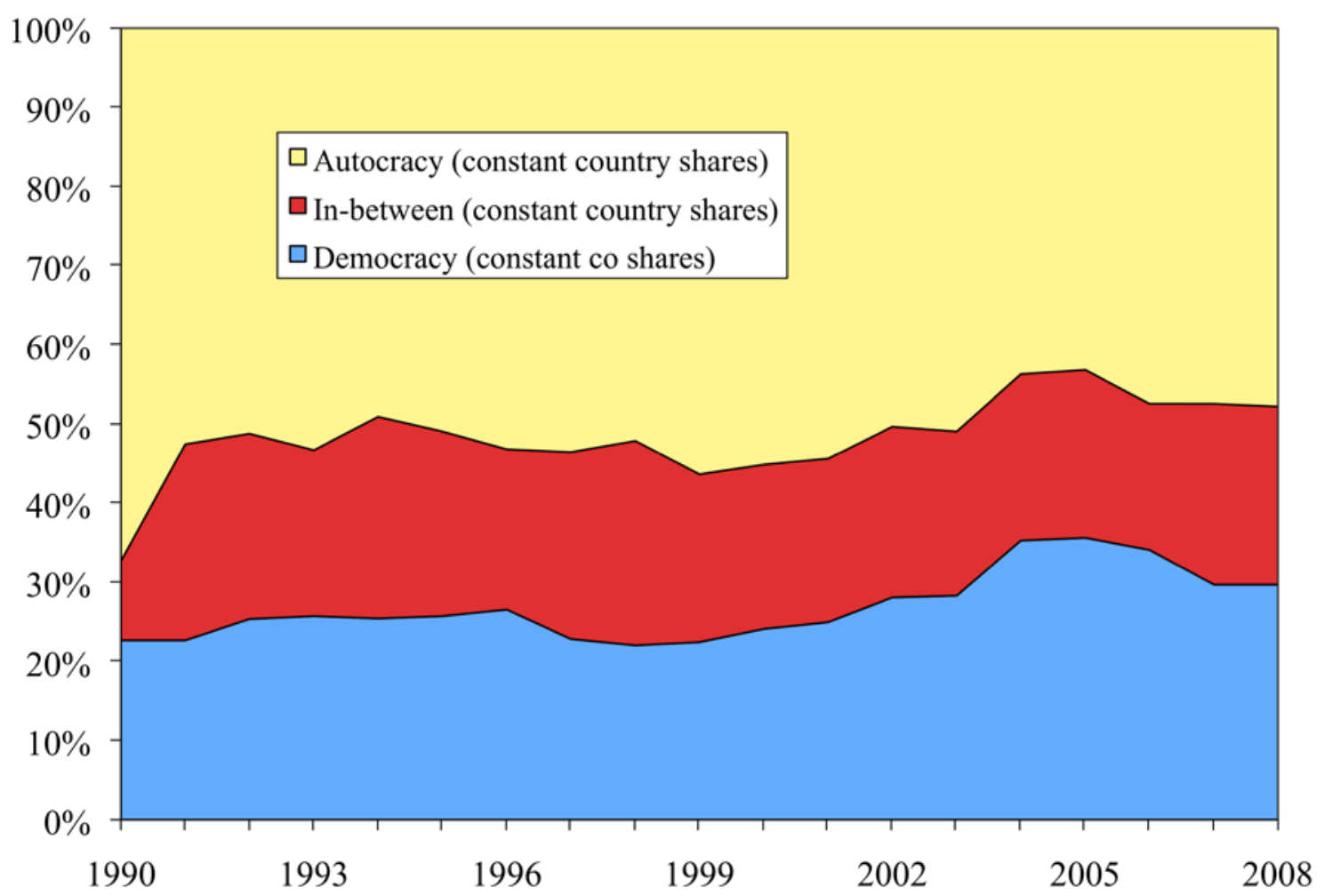

Note: Source is Polity IV. Democracy equals a score of 8, 9, or 10 from democ, autocracy equals a positive score on autoc, and in between is the rest. 
Figure 9: Aid Allocation Based on Income 1960-2008

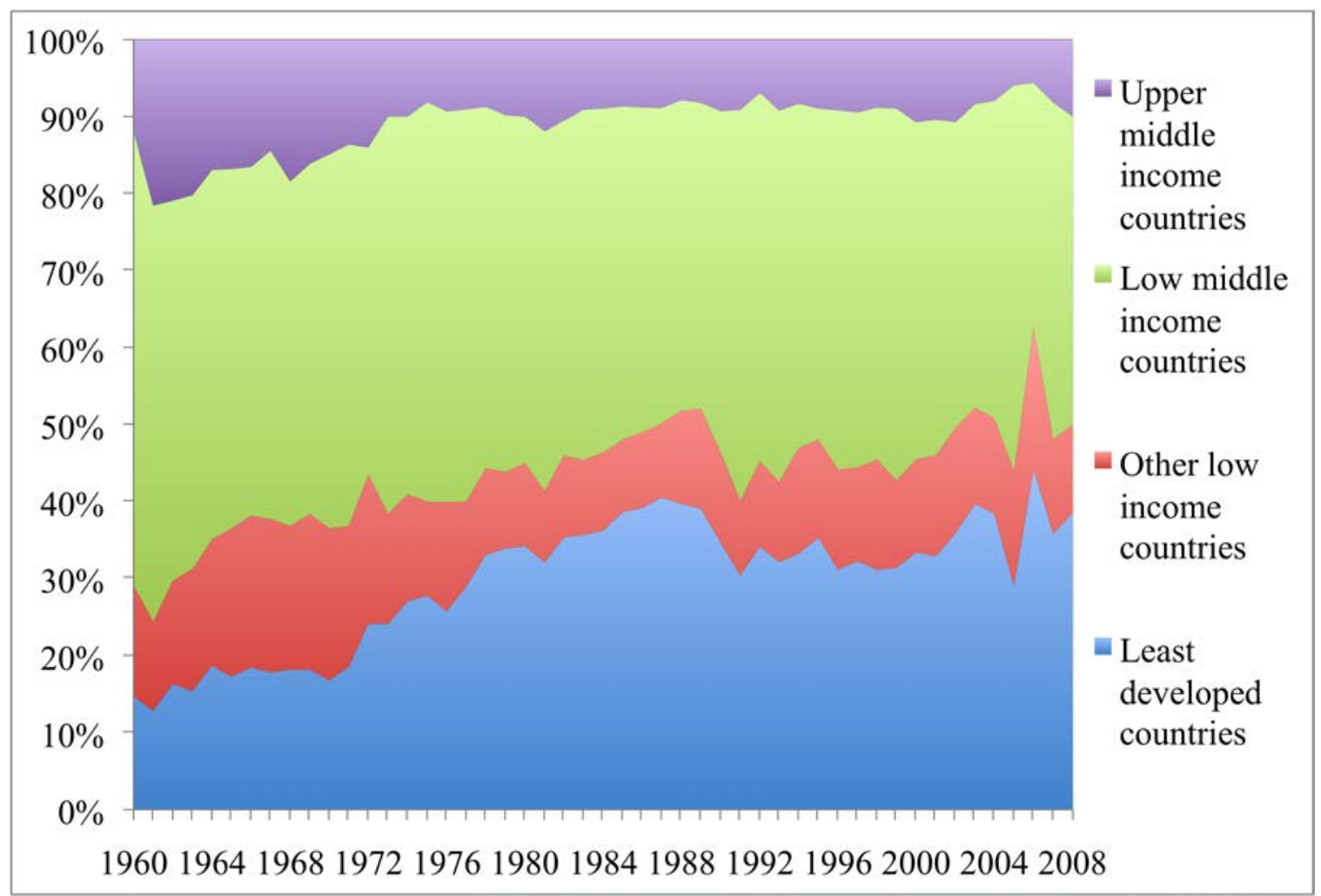

Note: Data from OECD DAC. Country classification based on OECD; other low income countries = less than $\$ 935$ GNI per capita in 2007; lower middle income countries = GNI per capita between \$936-3,705 in 2007; upper middle income countries = GNI per capita between \$3,706-11,455 in 2007. 
Figure 10: Share of Aid to Ineffective Channels 1979-2008

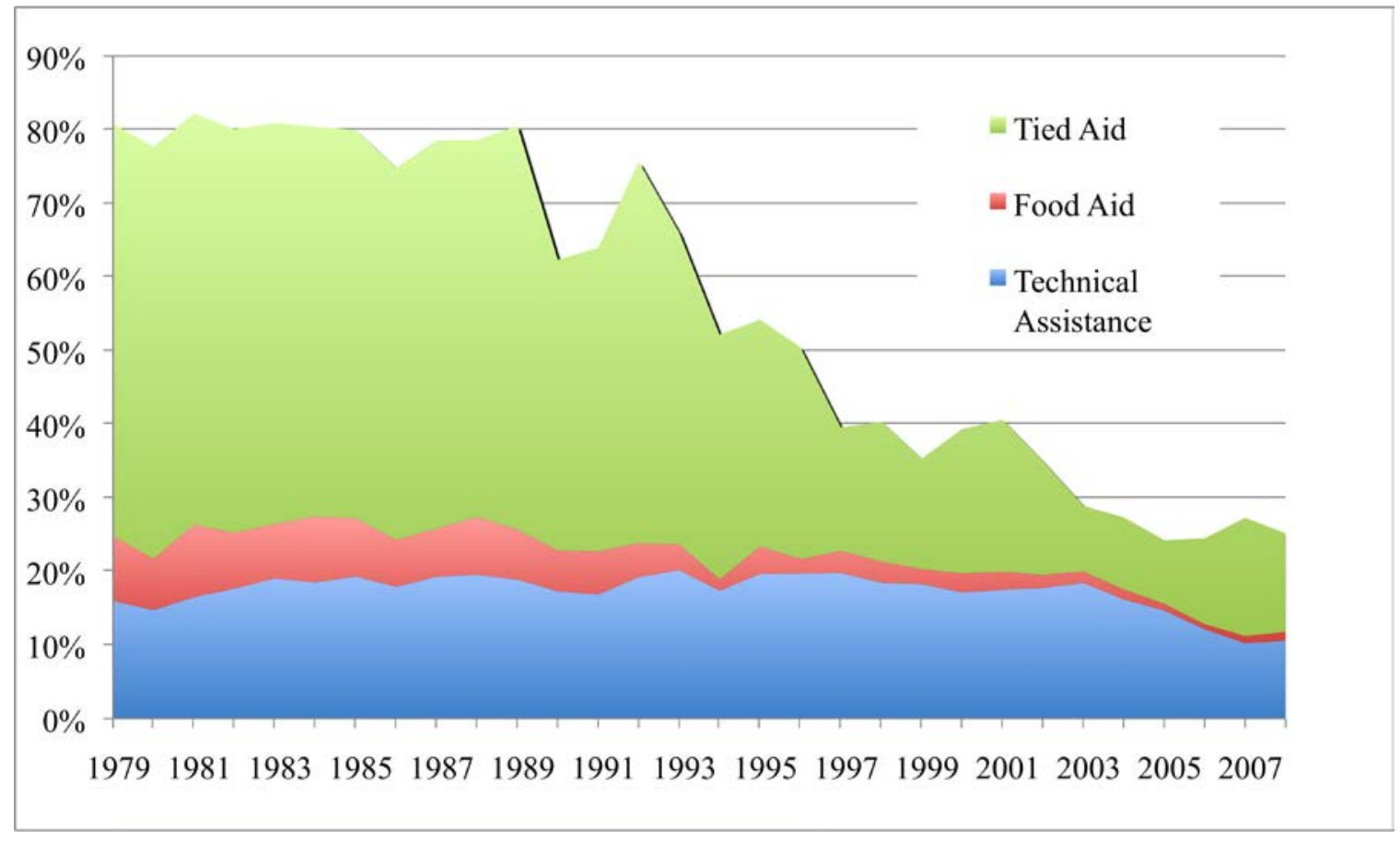

Note: Data from OECD DAC. 
Table 7: Ranking of Donor Agencies 2008

\begin{tabular}{|c|c|c|c|c|c|c|c|}
\hline Donor & $\begin{array}{c}\text { Percentile } \\
\text { Rank of } \\
\text { Overall } \\
\text { Percent } \\
\text { Rank } \\
\end{array}$ & $\begin{array}{l}\text { Specia- } \\
\text { lization } \\
\end{array}$ & $\begin{array}{c}\text { Selec- } \\
\text { tivity } \\
\end{array}$ & $\begin{array}{c}\text { I neffective } \\
\text { Channels } \\
\end{array}$ & $\begin{array}{l}\text { Over- } \\
\text { head } \\
\end{array}$ & $\begin{array}{c}\text { Trans- } \\
\text { parency }\end{array}$ & $\begin{array}{c}\text { Avg. of } \\
\text { Percent } \\
\text { Ranks } \\
\end{array}$ \\
\hline \multicolumn{8}{|l|}{ Bilateral Agency } \\
\hline United Kingdom & 5 & $34 \%$ & $80 \%$ & $70 \%$ & $83 \%$ & $82 \%$ & $70 \%$ \\
\hline Japan & 6 & $54 \%$ & $71 \%$ & $41 \%$ & $95 \%$ & $57 \%$ & $63 \%$ \\
\hline New Zealand & 8 & $41 \%$ & $95 \%$ & $63 \%$ & $44 \%$ & $66 \%$ & $62 \%$ \\
\hline Germany & 9 & $51 \%$ & $44 \%$ & $59 \%$ & $98 \%$ & $57 \%$ & $62 \%$ \\
\hline I reland & 11 & $44 \%$ & $61 \%$ & $85 \%$ & $78 \%$ & $36 \%$ & $61 \%$ \\
\hline Australia & 12 & $56 \%$ & $78 \%$ & $4 \%$ & $90 \%$ & $66 \%$ & $59 \%$ \\
\hline Netherlands & 13 & $17 \%$ & $32 \%$ & $67 \%$ & $93 \%$ & $82 \%$ & $58 \%$ \\
\hline Luxembourg & 14 & $37 \%$ & $85 \%$ & $81 \%$ & $17 \%$ & $61 \%$ & $56 \%$ \\
\hline \multicolumn{7}{|l|}{ European } & $54 \%$ \\
\hline Commission & 16 & $39 \%$ & $83 \%$ & $22 \%$ & $59 \%$ & $66 \%$ & $54 \%$ \\
\hline Denmark & 19 & $44 \%$ & $66 \%$ & $74 \%$ & $39 \%$ & $36 \%$ & $52 \%$ \\
\hline Italy & 22 & $80 \%$ & $2 \%$ & $56 \%$ & $73 \%$ & $36 \%$ & $50 \%$ \\
\hline Canada & 23 & $27 \%$ & $51 \%$ & $7 \%$ & $76 \%$ & $82 \%$ & $49 \%$ \\
\hline Austria & 24 & $95 \%$ & $0 \%$ & $48 \%$ & $32 \%$ & $66 \%$ & $48 \%$ \\
\hline France & 26 & $17 \%$ & $41 \%$ & $44 \%$ & $46 \%$ & $82 \%$ & $46 \%$ \\
\hline United States & 28 & $44 \%$ & $12 \%$ & $37 \%$ & $54 \%$ & $80 \%$ & $45 \%$ \\
\hline Portugal & 29 & $68 \%$ & $34 \%$ & $0 \%$ & $85 \%$ & $36 \%$ & $45 \%$ \\
\hline Sweden & 30 & $12 \%$ & $20 \%$ & $93 \%$ & $61 \%$ & $27 \%$ & $42 \%$ \\
\hline Switzerland & 32 & $17 \%$ & $22 \%$ & $78 \%$ & $49 \%$ & $36 \%$ & $40 \%$ \\
\hline Spain & 34 & $10 \%$ & $49 \%$ & $19 \%$ & $80 \%$ & $36 \%$ & $39 \%$ \\
\hline Finland & 36 & $12 \%$ & $68 \%$ & $15 \%$ & $71 \%$ & $20 \%$ & $37 \%$ \\
\hline Belgium & 37 & $29 \%$ & $27 \%$ & $33 \%$ & $41 \%$ & $55 \%$ & $37 \%$ \\
\hline Greece & 39 & $61 \%$ & $7 \%$ & $11 \%$ & $27 \%$ & $36 \%$ & $28 \%$ \\
\hline Average & 21 & $40 \%$ & $46 \%$ & $48 \%$ & $65 \%$ & $53 \%$ & $50 \%$ \\
\hline \multicolumn{8}{|l|}{$\begin{array}{l}\text { Multilateral } \\
\text { Agency }\end{array}$} \\
\hline Nordic Dev. Fund & 1 & $85 \%$ & $76 \%$ & & $88 \%$ & $66 \%$ & $79 \%$ \\
\hline Global Fund & 2 & $88 \%$ & $88 \%$ & & $68 \%$ & $64 \%$ & $77 \%$ \\
\hline Asian Dev. Bank & 3 & $73 \%$ & $90 \%$ & & $51 \%$ & $82 \%$ & $74 \%$ \\
\hline African Dev. Bank & 4 & $78 \%$ & $59 \%$ & & $66 \%$ & $82 \%$ & $71 \%$ \\
\hline IDA (World Bank) & 10 & $7 \%$ & $100 \%$ & & $56 \%$ & $82 \%$ & $61 \%$ \\
\hline $\begin{array}{l}\text { IDB } \\
\text { IMF }\end{array}$ & 18 & $63 \%$ & $15 \%$ & $52 \%$ & $63 \%$ & $66 \%$ & $52 \%$ \\
\hline (SAF,ESAF,PRGF) & 20 & $66 \%$ & $93 \%$ & & $12 \%$ & $30 \%$ & $50 \%$ \\
\hline EBRD & 21 & $83 \%$ & $10 \%$ & & $24 \%$ & $82 \%$ & $50 \%$ \\
\hline CariBank & 31 & $71 \%$ & $39 \%$ & & $22 \%$ & $36 \%$ & $42 \%$ \\
\hline GEF & 40 & $29 \%$ & $46 \%$ & & $5 \%$ & $9 \%$ & $22 \%$ \\
\hline Average & 15 & $64 \%$ & $61 \%$ & $52 \%$ & $46 \%$ & $60 \%$ & $58 \%$ \\
\hline
\end{tabular}




\begin{tabular}{|c|c|c|c|c|c|c|c|}
\hline \multicolumn{8}{|c|}{ UN Agency } \\
\hline UNRWA & 7 & $93 \%$ & $98 \%$ & & $37 \%$ & $25 \%$ & $63 \%$ \\
\hline UNFPA & 17 & $100 \%$ & $73 \%$ & & $7 \%$ & $30 \%$ & $52 \%$ \\
\hline UNDP & 25 & $76 \%$ & $63 \%$ & $96 \%$ & $2 \%$ & $2 \%$ & $48 \%$ \\
\hline UNI CEF & 27 & $59 \%$ & $24 \%$ & $100 \%$ & $34 \%$ & $14 \%$ & $46 \%$ \\
\hline IFAD (UN) & 33 & $2 \%$ & $54 \%$ & & $20 \%$ & $82 \%$ & $39 \%$ \\
\hline WFP & 35 & $98 \%$ & $56 \%$ & $26 \%$ & $0 \%$ & $14 \%$ & $39 \%$ \\
\hline UNAIDS & 38 & $90 \%$ & $5 \%$ & & $15 \%$ & $14 \%$ & $31 \%$ \\
\hline UNHCR & 41 & $5 \%$ & $29 \%$ & & $10 \%$ & $30 \%$ & $18 \%$ \\
\hline UNTA & 42 & $0 \%$ & $17 \%$ & $26 \%$ & & $2 \%$ & $11 \%$ \\
\hline Average & 29 & $58 \%$ & $47 \%$ & $62 \%$ & $16 \%$ & $23 \%$ & $39 \%$ \\
\hline
\end{tabular}


